\title{
1 A morphology independent methodology for quantifying planview river change and \\ 2 characteristics from remotely sensed imagery
}

4 Joel C. Rowland ${ }^{\mathrm{a}^{*}}$, Eitan Shelef ${ }^{\mathrm{a}}$, Paul A. Pope ${ }^{\mathrm{b}}$, Jordan Muss ${ }^{\mathrm{a}}$, Chandana Gangodagamage ${ }^{\mathrm{a}}$,

$5 \quad$ Steven P. Brumby ${ }^{\mathrm{c}}$, and Cathy J. Wilson ${ }^{\mathrm{a}}$

$6 \quad{ }^{a}$ Earth \& Environmental Sciences Division, MS-J495, Los Alamos National Laboratory, Los

7 Alamos, New Mexico, 87505. (jrowland@lanl.gov, shelefeitan@gmail.com, muss@lanl.gov,

8 chhandana@gmail.com, and cjw@lanl.gov)

9 b Intelligence \& Space Research Division, MS-B244, Los Alamos National Laboratory, Los

10 Alamos, New Mexico, 87505. (papope@lanl.gov)

$11{ }^{\mathrm{c}}$ Computer, Computational, and Statistical Sciences Division, MS-B244, Los Alamos National

12 Laboratory, Los Alamos, New Mexico, 87505. (steven@descarteslabs.com)

13 * Corresponding author: jrowland@lanl.gov, phone: 01 505-665-2871

15 Abstract

16 Remotely sensed imagery of rivers has long served as a means for characterizing channel

17 properties and detection of planview change. In the last decade the dramatic increase in the

18 availability of satellite imagery and processing tools has created the potential to greatly expand

19 the spatial and temporal scale of our understanding of river morphology and dynamics. To date,

20 the majority of GIS and automated analysis of planview changes in rivers from remotely sensed

21 data has been developed for single-threaded meandering river systems. These methods have

22 limited applicability to many of earth's rivers with complex multi-channel planforms. Here we

23 present the methodologies of a set of analysis algorithms collectively called Spatially Continuous 
24 Riverbank Erosion and Accretion Measurements (SCREAM). SCREAM analyzes planview river

25 metrics regardless of river morphology. These algorithms quantify both the erosion and accretion

26 rates of riverbanks from binary masks of channels generated from imagery acquired at two time

27 periods. Additionally, the program quantifies the area of change between river channels and the

28 surrounding floodplain and area of islands lost or formed between these two time periods. To

29 examine variations in erosion rates in relation to local channel attributes and make rate

30 comparisons between river systems of varying sizes, the program determines channel widths and

31 bank curvature at every bank pixel. SCREAM was developed and tested on rivers with diverse

32 and complex planform morphologies in imagery acquired from a range of observational

33 platforms with varying spatial resolutions. Validation and verification of SCREAM-generated

34 metrics against manual measurements shows no significant measurement errors in determination

35 of channel width, erosion, and bank aspects. SCREAM has the potential to provide data for both

36 the quantitative examination of the controls on erosion rates and for the comparison of these

37 rates across river systems ranging broadly in size and planform morphology. 


\section{Introduction}

The analysis of river planform properties and dynamics has long used aerial photography

41 and increasingly incorporates satellite imagery. Traditionally, extracting a representation of a

42 river, such as banklines or a centerline, relied on labor-intensive efforts by a human analyst to

43 digitize the river channel. The development of supervised and semi-automated methodologies for

44 extracting a binary representation of rivers from pixel-based images (e.g. Brumby et al., 1999;

45 Dey \& Bhattacharya, 2013; Dillabaugh, Niemann, \& Richardson, 2002; Hamilton et al., 2007;

46 Marra, Kleinhans, \& Addink, 2014; McFeeters, 1996; Merwade, 2007; Quackenbush, 2004;

47 Smith \& Pavelsky, 2008; Xu, 2006) and the wealth of freely available imagery offers the

48 potential to greatly expand both the temporal and spatial scale of river analysis (Fisher,

49 Bookhagen, \& Amos, 2013). In response to the greater availability of imagery, expanded use of

50 Geographic Information Systems (GIS) and image processing software packages, a number of

51 published and freely distributed methodologies for extracting river metrics from imagery have

52 become available over the past decade. Examples of such tools include, but are not limited to, the

53 ArcGIS-based River Planform Statistics Toolbox (Aalto, Lauer, \& Dietrich, 2008), the

54 Interactive Data Language (IDL)-based RivWidth code (Pavelsky \& Smith, 2008), the Matlab-

55 based width and centerline ChanGeom code (Fisher, Bookhagen, \& Amos, 2013), and Matlab-

56 based channel centerline and curvature codes (Legleiter \& Kyriakidis, 2006). Table 1 provides a

57 representative summary of the range of measurements these and other published methodologies

58 generate. The ever-expanding availability of high-resolution topographic data has led to the

59 development of geomorphic change detection (GCD) and DEMs of difference (DoD) methods to

60 quantify both lateral and vertical changes in river systems (James et al., 2012; Wheaton et al.,

61 2010). The temporal and spatial availability of data sets needed for this type of analysis, 
62 however, are still limited enough that the analysis of remotely sensed imagery remains a critical 63 tool for studies of multi-temporal river dynamics.

64 Current methodologies have the potential to add great efficiency to the analysis task of

65 river planview metrics, but a lack of method standardization in river change studies still persists

66 (Hooke, 1980; Lawler, 1993; Peixoto, Nelson, \& Wittmann, 2009). This problem arises from

67 variation in data sources, analysis tools, and the objectives of the individual studies. This lack of

68 methodological consistency between studies greatly confounds inter-study comparisons and data

69 compilation efforts. Furthermore, the diversity of metrics used to quantify change complicates

70 the comparison of results of planview river changes between studies. Reported measures include:

71 lateral migration, erosion, accretion, area change as a percentage of river area, change in area per

72 unit river length, river path length, sinuosity, curvature, radius of curvature, width, and areal

73 changes in river channel position (Table 1). Bank erosion and channel migration rates represent

74 the most commonly reported metrics and can be, but are not necessarily, synonymous. Bank

75 erosion measurements quantify the material removed from the exposed face of a riverbank, and

76 are reported as a linear distance per interval of time (e.g., meter (m) per year (yr)). Channel

77 migration measures the net movement of a channel resulting from the change in river location

78 due to the combined effects of erosion and deposition (Leopold, 1973; Leys \& Werritty, 1999).

79 Numerous studies using remotely sensed data have determined lateral migration rates

80 based on the lateral change in the river centerline position, commonly calculated as the midpoint

81 between opposite banks (e.g. Aalto, Lauer, \& Dietrich, 2008; Constantine et al., 2014; Konrad et

82 al., 2011; Lauer \& Parker, 2008b; Legleiter \& Kyriakidis, 2006; Mount \& Louis, 2005; Shields,

83 Simon, \& Steffen, 2000) or directly digitized by the analyst (e.g. Brice, 1977; Constantine,

84 Dunne, \& Hanson, 2009; Hooke \& Harvey, 1983; Hooke \& Yorke, 2010; Micheli, Kirchner, \& 
85 Larsen, 2004; Micheli \& Larsen, 2011; Micheli \& Kirchner, 2002). For a single-threaded

86 channel with a constant width and no positional errors in bank location, the change in the

87 position of the centerline should accurately reflect bank erosion (Figure 1a). Hooke \& Yorke

88 (2010) and Parker et al. (2011), however, point out that in many migrating river channels, the

89 erosion and accretion of banks become temporally out of phase. A channel may widen in

90 response to bank erosion followed by a corresponding bank accretion on the opposing bank

91 causing the channel to then narrow resulting in temporal width variations. A centerline derived

92 from a channel in which the position of only one side of the channel has moved over the time

93 interval examined will reflect only half the actual change in the bank erosion (or accretion)

94 (Figure 1b). Additionally, in river channels experiencing widening or narrowing due to erosion

95 or accretion on both sets of banks, channel migration estimates derived from centerlines will

96 only measure the difference, not the total magnitude, in the widening and narrowing occurring on

97 opposite banks. In a situation where the widening or narrowing occurs equally on opposing

98 banks, there will be no recorded migration of the channel centerline (Figure 1c). Therefore, in

99 studies and modeling efforts examining the rate of movement of a channel as a whole, migration

100 rates derived from centerlines represent an appropriate and accurate metric. However, in studies

101 that quantify sediment exchange to and from floodplains or the dynamics of bank erosion,

102 migration rates of channel centerlines may not fully capture the dynamics of the system.

103 Additionally, recent advances in modeling of river channel erosion and migration treat the

104 dynamics of opposing banks independently (Asahi et al., 2013; Eke, Parker, \& Shimizu, 2014;

105 Eke et al., 2014; Parker et al., 2011; Zolezzi, Luchi, \& Tubino, 2012a), thereby necessitating

106 measurement techniques that quantify bank changes independent of the net movement of the

107 channel centerline. 


\begin{tabular}{|c|c|c|c|c|c|c|c|c|c|c|}
\hline & \multicolumn{10}{|c|}{ vietion } \\
\hline & $\begin{array}{c}\text { Planform } \\
\text { Statistic } \\
\text { Toolbox }^{1}\end{array}$ & RivWidth $^{2}$ & ChanGeom & $\begin{array}{l}\text { Centerline } \\
\text { Polygons }^{4}\end{array}$ & $\begin{array}{l}\text { Centerline } \\
\text { Curvature }^{5}\end{array}$ & $\begin{array}{c}\text { Area Based } \\
\text { Change }^{6}\end{array}$ & $\mathrm{CWT}^{7}$ & $\begin{array}{c}\text { Outer bank } \\
\text { displacement }^{8}\end{array}$ & SCREAM & $\begin{array}{l}\text { SCREAM } \\
\text { Output }\end{array}$ \\
\hline Morphology & $\mathrm{S}$ & $\mathrm{S} / \mathrm{M}$ & $\mathrm{S}$ & $\mathrm{S}$ & $\mathrm{S}$ & $\mathrm{S} / \mathrm{M}$ & $\mathrm{M}$ & $\mathrm{M}$ & $\mathrm{S} / \mathrm{M}$ & \\
\hline Metric & & & & & & & & & & \\
\hline $\begin{array}{l}\text { Linear rates of lateral } \\
\text { channel migration }\end{array}$ & Intervals & -- & -- & Polygons & -- & -- & -- & -- & -- & -- \\
\hline $\begin{array}{c}\text { Linear rate of bank } \\
\text { erosion }\end{array}$ & -- & -- & -- & -- & -- & -- & -- & XS & $\begin{array}{c}-- \\
\text { Bank pixel/ segment averages }\end{array}$ & $\begin{array}{c}-- \\
\text { Raster/Text }\end{array}$ \\
\hline $\begin{array}{c}\text { Linear rate of bank } \\
\text { accretion }\end{array}$ & -- & -- & -- & -- & -- & -- & -- & -- & Bank pixel/ segment averages & Raster/Text \\
\hline Area of erosion & -- & -- & -- & -- & -- & Entire river reach & -- & -- & Entire river reach/ segments & Text \\
\hline Area of accretion & -- & -- & -- & -- & -- & Entire river reach & -- & -- & Entire river reach/ segments & Text \\
\hline $\begin{array}{l}\text { Change as \% of } \\
\text { channel area }\end{array}$ & -- & -- & -- & -- & -- & Entire river reach & -- & -- & Entire river reach/segments & Text \\
\hline $\begin{array}{l}\text { Percentage of banks } \\
\text { eroding and accreting }\end{array}$ & -- & -- & -- & -- & -- & -- & -- & -- & Segments & Text \\
\hline $\begin{array}{l}\text { Spatial and temporal } \\
\text { patterns of bank } \\
\text { change }\end{array}$ & -- & -- & -- & -- & -- & -- & XS & -- & -- & -- \\
\hline Channel Width & Intervals & $\mathrm{CP}$ & $\mathrm{CP}$ & -- & -- & -- & -- & -- & Bank pixel/ Segment averages & Raster/Tex \\
\hline $\begin{array}{l}\text { Total width of multi- } \\
\text { thread channels }\end{array}$ & -- & $\mathrm{CP}$ & -- & -- & -- & -- & -- & XS & Segment averages & Text \\
\hline Centerline curvature & Intervals & -- & -- & -- & Continuous & -- & -- & -- & -- & -- \\
\hline Bank curvature & -- & -- & -- & -- & -- & -- & -- & -- & Bank pixel & Raster/Text \\
\hline Bank aspect & -- & -- & -- & -- & -- & -- & -- & -- & Bank pixel & Raster/Text \\
\hline Sinuosity & -- & -- & -- & -- & -- & -- & -- & -- & Continuous/ Segment averages & Text \\
\hline Channel Elongation & Intervals & -- & -- & -- & -- & -- & -- & -- & -- & -- \\
\hline Number of Islands & -- & -- & -- & -- & -- & -- & -- & -- & Segments & Text \\
\hline Total Island Area & -- & -- & -- & -- & -- & -- & -- & -- & Segments & Text \\
\hline Total Length of Banks & -- & -- & -- & -- & -- & -- & -- & -- & Segments & Text \\
\hline $\begin{array}{l}\text { Total Length of } \\
\text { Island Perimeters }\end{array}$ & -- & -- & -- & -- & -- & -- & -- & -- & Segments & Text \\
\hline $\begin{array}{c}\text { Number and location } \\
\text { of cutoffs and } \\
\text { avulsions }\end{array}$ & -- & -- & -- & -- & -- & -- & -- & -- & Entire river reach & Text \\
\hline
\end{tabular}

$\mathrm{S}$ - Single-thread channe

$\mathrm{M}$ - Multi-thread channe

$\mathrm{XS}-$ Cross section

$\mathrm{CP}$ - Centerline Pixel

(Aalto, Lauer, \& Dietrich, 2008; Lauer \& Parker, 2008b); ${ }^{2}$ (Pavelsky \& Smith, 2008); ${ }^{3}$ (Fisher, Bookhagen, \& Amos, 2013); ${ }^{4}$ (Micheli, Kirchner, \& Larsen, 2004; Micheli \& Kirchner, 2002); ${ }^{5}$

(Güneralp \& Rhoads, 2008; Legleiter \& Kyriakidis, 2006); ${ }^{6}$ (Peixoto, Nelson, \& Wittmann, 2009); ${ }^{7}$ Continuous Wavelet Transforms (Mount et al., 2012); ${ }^{8}$ (Baki \& Gan, 2012; Hossain, Gan, \& Baki, 2013) 


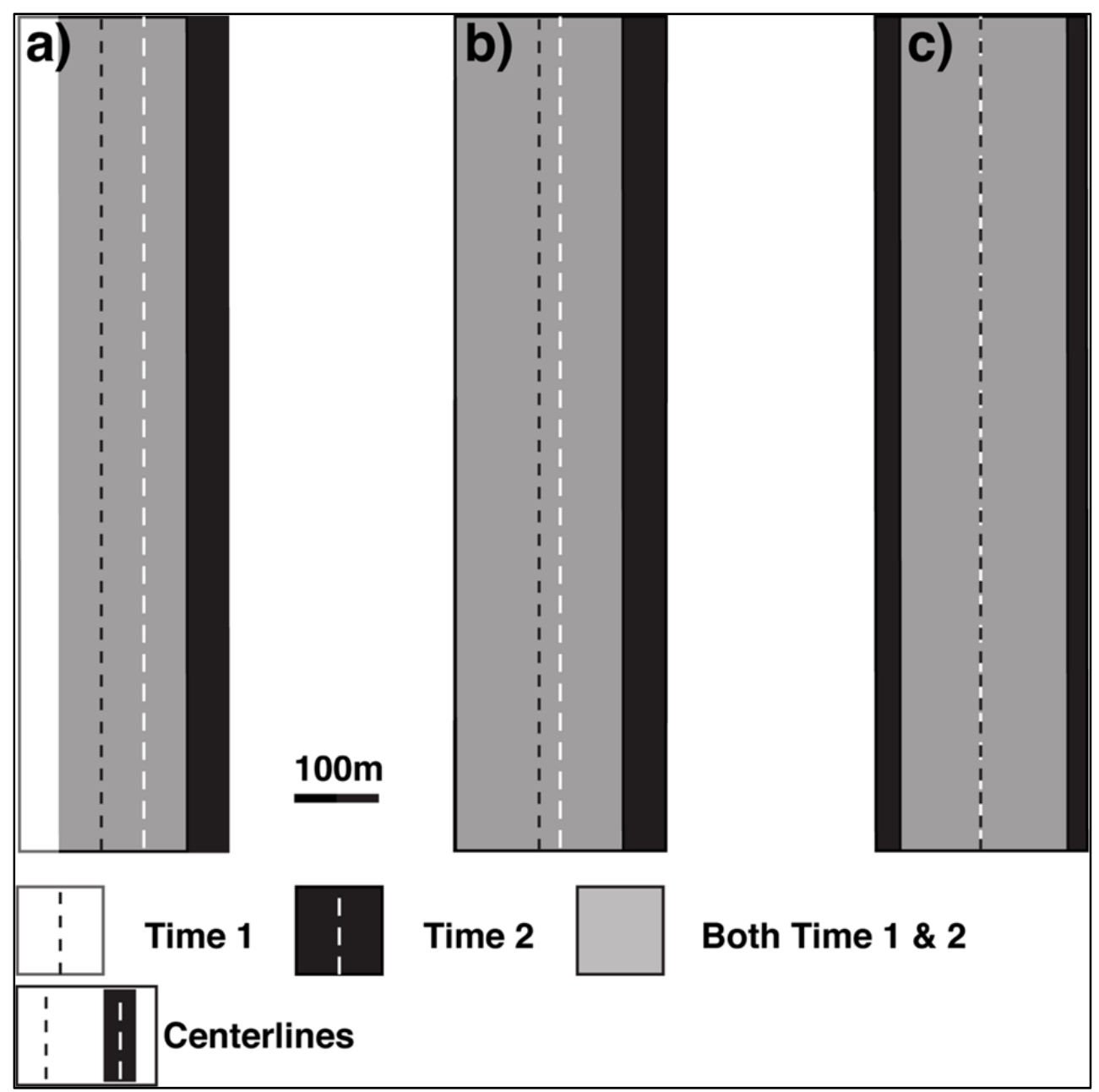

118 Figure 1: Three hypothetical changes in channel position between Time 1 and Time 2 having equal areas of erosion of the bounding floodplain but differing channel centerline migration (dashed lines). a) The channel shifts laterally $50 \mathrm{~m}$, with equal areas of erosion and deposition on opposite sides of the channel. b) The channel at Time 2 widens by $50 \mathrm{~m}$ on one side, the average linear erosion along the banks is $50 \mathrm{~m}$, but the migration of channel centerlines is only $25 \mathrm{~m}$. c) The channel widens by $50 \mathrm{~m}$ by eroding $25 \mathrm{~m}$ along each channel margin. The total erosion along the channel is the same as a and $b$, but the migration of the centerline indicates $0 \mathrm{~m}$ of change.

While effective methodologies have been developed and applied to quantify channel widths in multi-threaded channel systems (Allen \& Pavelsky, 2015; Pavelsky \& Smith, 2008;

Yamazaki et al., 2014), the majority of methods developed for analyzing changes in planview

130 river properties from remotely sensed imagery were developed for and applied to single-threaded 
131 meandering channel systems (Table 1). These methods have limited applicability to multi-

132 threaded systems with complex planform geometries. This limitation greatly restricts the size and

133 global extent of river analysis efforts. The earth's mega rivers (as defined by Latrubesse (2008)

134 as having mean annual discharges $>17,000 \mathrm{~m}^{3} / \mathrm{s}$ ), with the exception of the Mississippi River,

135 have complex multi-thread channel patterns (Ashworth \& Lewin, 2012; Latrubesse, 2008). Many

136 smaller river systems also have complex multi-threaded channel forms. The limited number of

137 studies that have explored planview change in multi-threaded river systems used varied methods

138 and metrics creating a challenge for inter-river comparisons. For example, Mount et al. (2012)

139 provided a wavelet-based analysis of bank line retreat on the Jamuna River, Bangladesh. This

140 study quantified the displacement of the system's outermost banks normal to the dominant

141 orientation of the river channel belt, but did not examine bank erosion within the network of

142 river channel threads. Similarly, measurements of outer bank displacements of the Jamuna River

143 and the Ganges were made on evenly spaced cross-sections oriented orthogonally to the valley

144 axis (Baki \& Gan, 2012; Hossain, Gan, \& Baki, 2013). Other research on the Jamuna used a

145 network centrality approach to characterize the structure and variability of the channel belt, but

146 did not explore bank erosion rates (Marra, Kleinhans, \& Addink, 2014). Studies of the Lena

147 River, Russia have measured bank erosion rates and bank movement rates, but the details of the

148 methodology were not described (Costard \& Gautier, 2008; Costard et al., 2007; Gautier et al., 149 2003).

150 Motivated by the need to measure planview changes of complex multi-threaded rivers,

151 we developed a set of algorithms to analyze these changes using aerial photographs and satellite

152 imagery. We have named this set of algorithms Spatially Continuous Riverbank Erosion \&

153 Accretion Measurements (SCREAM). Given the importance of bank properties (Thorne \& 
154 Tovey, 1981) and the local flow conditions (Darby et al., 2010; Kean \& Smith, 2006a, b) on

155 bank erosion rates, and the challenge of delineating centerlines in multi-threaded rivers, we

156 adopted a bank-centered reference frame for measuring change. SCREAM generates a suite of

157 measurements related to planview attributes of the channel, such as width, bank curvature,

158 sinuosity, and bank aspects, as well as, metrics to quantify changes in channel and floodplain

159 area and linear rates of changes in bank position over time (Table 1). These metrics may be

160 determined at a scale as fine as the pixel resolution of the input imagery, and binned in regularly

161 spaced intervals along the channel for examination of spatial patterns of river morphology and

162 dynamics. Table 1 summarizes additional metrics related to planview characteristics of rivers

163 calculated by SCREAM.

164 This paper aims to provide a clear description of the methodologies used to generate the 165 range of metrics output by the SCREAM algorithms. This description will aid in the proper use

166 of SCREAM by other researchers and allow for critical evaluation of the unique set SCREAM-

167 generated outputs in future studies of river morphology and dynamics. Following the description

168 of SCREAM methodologies, we apply SCREAM to a range of natural river systems to illustrate

169 the output and place the metrics in the context of previously published methods and remote

170 sensing based studies of rivers. We present an accuracy assessment of these example results by

171 comparing SCREAM results to manually derived measurements. We supplement the results of

172 this accuracy assessment with a comparison of SCREAM against existing algorithms for the

173 measurement of lateral river channel migration, river channel curvature, and channel width.

174 These comparisons allow for the evaluation of the comparability of SCREAM metrics relative to

175 alternative methodologies and provide additional confidence in the reliability of SCREAM 
176 output. We conclude with a discussion of what we perceive to be the relative strengths and

177 limitations of SCREAM and areas for future evaluation and code refinement.

\section{2. Methods}

179 SCREAM incorporates a collection of scripts written in IDL, a commercially available

180 software package licensed by ExelisVis. IDL-based applications may be run using the IDL

181 Virtual Machine without a license. SCREAM requires two georeferenced binary masks of the

182 river channel at two successive dates with pixels projected onto a common uniform grid of

183 identical dimensions and resolutions. In these masks, river channel pixels have a value of one

184 while all non-river channel pixels equal zero. Rather than digitizing the extents of river channels

185 from imagery, we derived the channel masks from automated feature extraction software trained

186 to identify river pixels in remotely sensed imagery. Mask generation occurs outside of SCREAM

187 and the choice of masking methodology is not critical to the use of SCREAM. Binary masks of

188 river channels may be generated using a variety of techniques (Brumby et al., 1999; Dey \&

189 Bhattacharya, 2013; Dillabaugh, Niemann, \& Richardson, 2002; Fisher, Bookhagen, \& Amos,

190 2013; Hamilton et al., 2007; Marra, Kleinhans, \& Addink, 2014; McFeeters, 1996; Merwade,

191 2007; Quackenbush, 2004; Smith \& Pavelsky, 2008; Xu, 2006; Zolezzi, Luchi, \& Tubino,

192 2012b) though ones that rely on a spectral threshold for water to define the channel may suffer

193 errors in estimating consistent bankfull extents with imagery acquired at times of differing river

194 stages. However, if a user inputs river masks derived from the wetted extent of a river at

195 different times with varying river stage, from other data sources, SCREAM could be used to

196 calculate stage-area relationships useful for estimation of river discharge or hydrological

197 modeling (Gleason \& Smith, 2014; Smith \& Pavelsky, 2008). 
To minimize errors in bankfull channel extent associated with variations in river stage we

199 extracted river channels based on criteria aimed at identifying the physical boundaries of the

200 channel (Figure 2a). In our classification, we considered both open water and bare sand/gravel as

201 river channel, while vegetated pixels were classified as non-river. Numerous prior studies of

202 river channels have used this classification approach to delineate bankfull channel extents

203 independent of river stage (Aalto, Lauer, \& Dietrich, 2008; Fisher, Bookhagen, \& Amos, 2013;

204 Gurnell, 1997a; Gurnell, 1997b; Lauer \& Parker, 2008b; Mount \& Louis, 2005; Peixoto, Nelson,

205 \& Wittmann, 2009; Richard, Julien, \& Baird, 2005; Winterbottom \& Gilvear, 2000). While

206 seasonal changes in vegetation cover and overhanging vegetation potentially result in uncertainty

207 in the delineation of channel banks (Gurnell, 1997b; Mount \& Louis, 2005), this method

208 generally provides a consistent set of criteria for defining channel extents independent of river

209 discharge. This approach inherently assumes that any region or bank within the channel that has

210 exposed sediment experiences flow and sediment transport frequently enough to inhibit the

211 colonization of vegetation. Therefore it experiences flow at time intervals that are within the

212 common hydrological definition of bankfull flow (at least once every few years)(Knighton,

213 1998). In arid regions or other areas with sparse vegetation or infrequent channel clearing flows

214 this assumption requires careful consideration.

215 To derive the binary channel masks used in this study, we used the supervised automated

216 feature extraction software package GeniePro (Brumby et al., 1999; Perkins et al., 2005) which is

217 commercially available from Observera Inc. and allows for the automated delineation of the full

218 extent of a river channel (wetted and dry exposed portions of the channel bed) using all available

219 spectral bands of the imagery based on a user defined set of training data. In addition to spectral

220 content, GeniePro uses spatial context of pixels in the user-defined training regions to identify 
221 distinct features within the imagery and can be trained to identify boundaries with variable

222 attributes such as shadowing and vegetation. In our experience, GeniePro largely, but not

223 completely, avoids the four significant hurdles to automated feature extraction of river channels

224 raised by Priestnall \& Aplin (2006): 1) determining the edge of the river; 2) channel boundaries

225 obscured by vegetation or shadows; 3) confusion with other linear features; and 4) context.
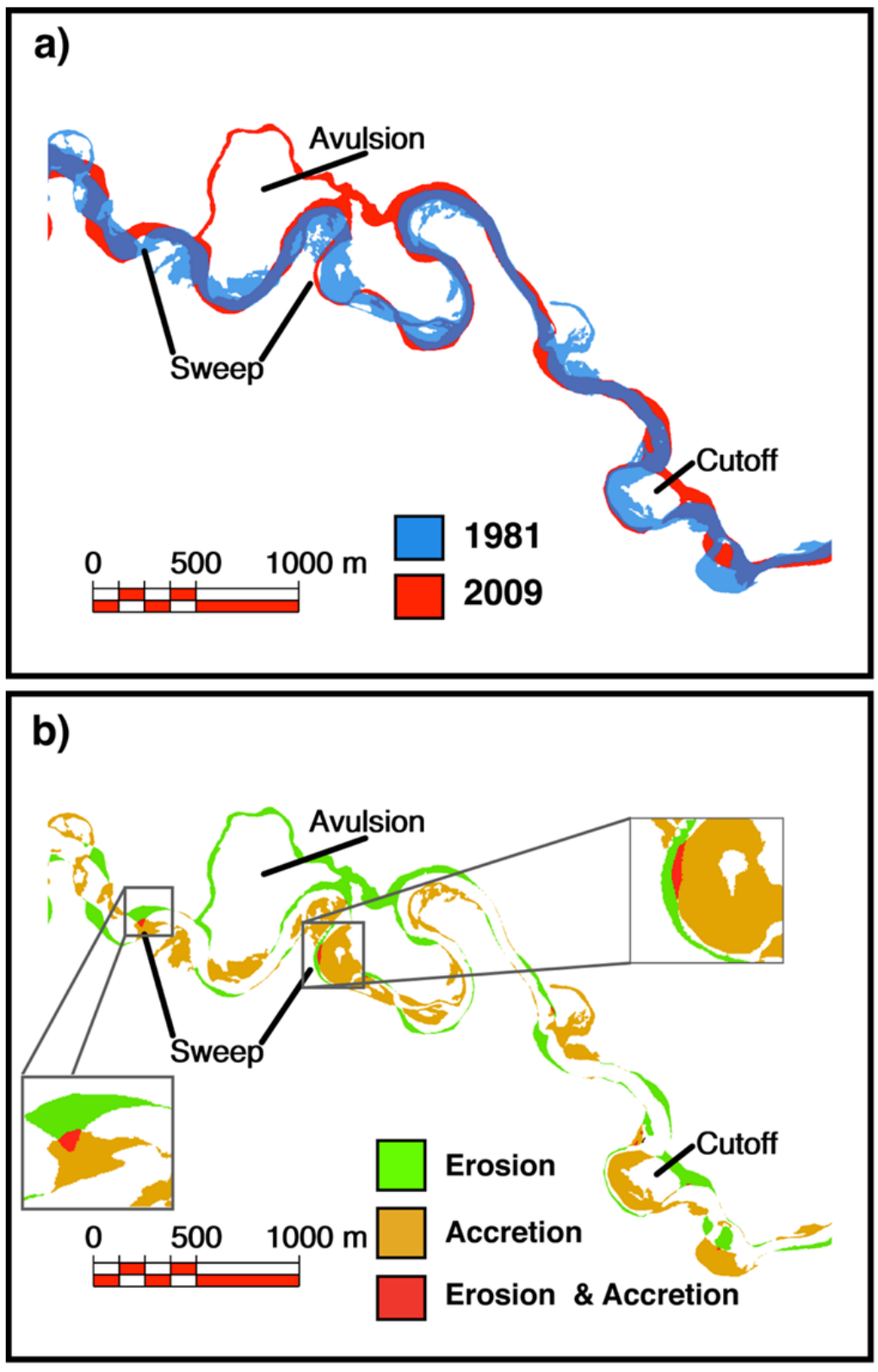

227 Figure 2: a) Two binary masks of a portion of the Selawik River, Alaska derived from 228 September 24 and 29, 2009 Geoeye images (red) and July 25, 1981 Alaska High Altitude

229 Photography (AHAP) (blue). Areas of red not overlain by the blue mask represent areas of the 
230 floodplain that eroded. Areas labeled "Sweep" mark places where the channel eroded more than 231 a channel width. Areas where the channel jumped to a new location are labeled as "Avulsion" or 232 "Cutoff". b) Areas experiencing erosion, accretion, and both erosion and accretion.

234 Automated channel delineations were followed by manual edits to remove classification errors, 235 eliminate areas affected by overhanging trees (evidenced by local outward irregularities in the 236 bank lines and visibly tilted trees) and to trim fragments of tributary channels connected to the 237 master channel of interest.

238 In addition to providing input rasters, the user needs to specify the dates of the imagery

239 (in decimal years) and identify the corner of the raster closest to the upstream end of the channel 240 mask. If the upstream end of the channel is near the middle of a raster boundary, then either

241 corner of that boundary may be specified. Program options include: the ability to segment the

242 channel rasters to calculate river change and attributes at regularly spaced intervals; specification

243 of the interval length; and the selection of a common reference frame for multi-temporal analyses

244 by providing an existing raster-based channel centerline for use in channel segmentation.

2452.1 Delineating areas of change between time periods

246 SCREAM generates a map of change in a river channel location between the acquisition

247 dates of the two images by differencing the two input rasters (Figure 2). Subtracting the Time 1

248 channel mask from the Time 2 channel mask generates a resultant raster with values of -1 for

249 regions of channel accretion, 0 for no change, and 1 for erosion. Based on these values,

250 SCREAM creates two separate change masks: erosion and accretion. Similar approaches were

251 employed in studies of river planview change in the Amazon basin using a raster-based approach

252 (Peixoto, Nelson, \& Wittmann, 2009; Rozo, Nogueira, \& Castro, 2014), and Gurnell,

253 Downward, \& Jones (1994) used a comparable polygon-based approach. Each mask is analyzed

254 separately but in an identical manner to quantify erosion and accretion, respectively. SCREAM 
255 uses the number of pixels in each of the erosion/accretion regions to quantify areas of change and

256 these measurements can be binned at regular intervals along the river channel (Section 2.5).

257 In a number of unique cases, the SCREAM analysis requires additional constraints to

258 accurately measure erosion and accretion. If a river channel migrates more than a full channel

259 width over the time interval between image acquisition, there will be regions of the mask that

260 show no change between the two images but have in fact changed from non-river to river and

261 back to non-river over this time period (Figure 2). This issue has also confounded prior area-

262 based analyses of planview change in rapidly migrating rivers (Peixoto, Nelson, \& Wittmann,

263 2009; Shields, Simon, \& Steffen, 2000).

264 Identification of the regions where the channel has migrated more than a channel width

265 becomes further complicated by instances in which the channel moves significant distances

266 across the floodplain by abrupt jumps (cutoffs and avulsions) rather than continuous migration.

267 The identification of such regions requires several screening steps. Areas undergoing both

268 erosion and accretion can be identified because the river channel pixels fully enclose them when

269 the river masks from the two time intervals are combined (Figure 2 - areas labeled "sweep"), but

270 islands present at both time periods also meet this criteria. SCREAM, however, labels the islands

271 in the initial input masks and excludes those pixels from further consideration. Next, to

272 differentiate between areas over which the river continuously swept from Time 1 to Time 2 from

273 areas where the river abruptly changed location through cutoff or avulsion, SCREAM compares

274 the average distance across the possible area of change to the average local width of the channels

275 bounding this area. SCREAM calculates this average distance by dividing the area of the region

276 by half of the area's perimeter length (Micheli, Kirchner, \& Larsen, 2004). If the average

277 distance across this bounded region is less than a user specified threshold (in units of local 
278 channel widths), that is based on the size of the river, the rates of migration expected, and the

279 time interval examined, then the change is considered to be a region where the channel has swept

280 across the floodplain and SCREAM adds this area to both the erosion and accretion masks (red

281 regions in Figure 2b). If the distance is greater than the threshold SCREAM marks these areas as

282 either a cutoff or avulsion.

283 Prior to differencing the channel masks, SCREAM performs a filtering operation to

284 remove the smallest islands in the mask. Changes associated with these features are the least

285 accurate because they have the greatest relative error in terms of the number of potentially

286 misclassified pixels (Supplemental Materials). The default filter threshold removes islands with

287 areas smaller than the island area corresponding to the 0.01 percentile in the cumulative

288 distribution of island sizes. The threshold was selected by trial and error to get rid of very small

289 islands (a few pixels in size). To prevent the removal of significant islands in a river with a very

290 uniform distribution of island sizes, a river must have more than 10 islands and the standard

291 deviation in island sizes must be more than half the mean island size for filtering to be

292 performed.

293 After differencing the masks, SCREAM also filters out single isolated pixels prior to

294 calculating change in bank locations and channel areas, similar to the approach of Serra, Pons, \&

295 Sauri (2003). As with small islands, changes associated with a single pixel have the potential to

296 have errors of similar magnitudes to the measured change due to both misregistration of imagery

297 and/or classification errors (Supplemental Materials).

2982.2 Linear rates of change

299 To examine the patterns and rates of change at the pixel scale and to generate metrics

300 comparable to prior studies, we calculate linear rates of bank erosion and accretion in units of 
301 (length (L) / time (T)) for every bank pixel in the input raster. The length used in these rates is

302 the distance from a bank pixel at Time 1 to the closest bank pixel at Time 2 that borders the same

303 region of channel change (Section 2.1) (Figure 3a). SCREAM employs identical methods for

304 calculating rates of erosion and accretion, using separate erosion and accretion change masks.
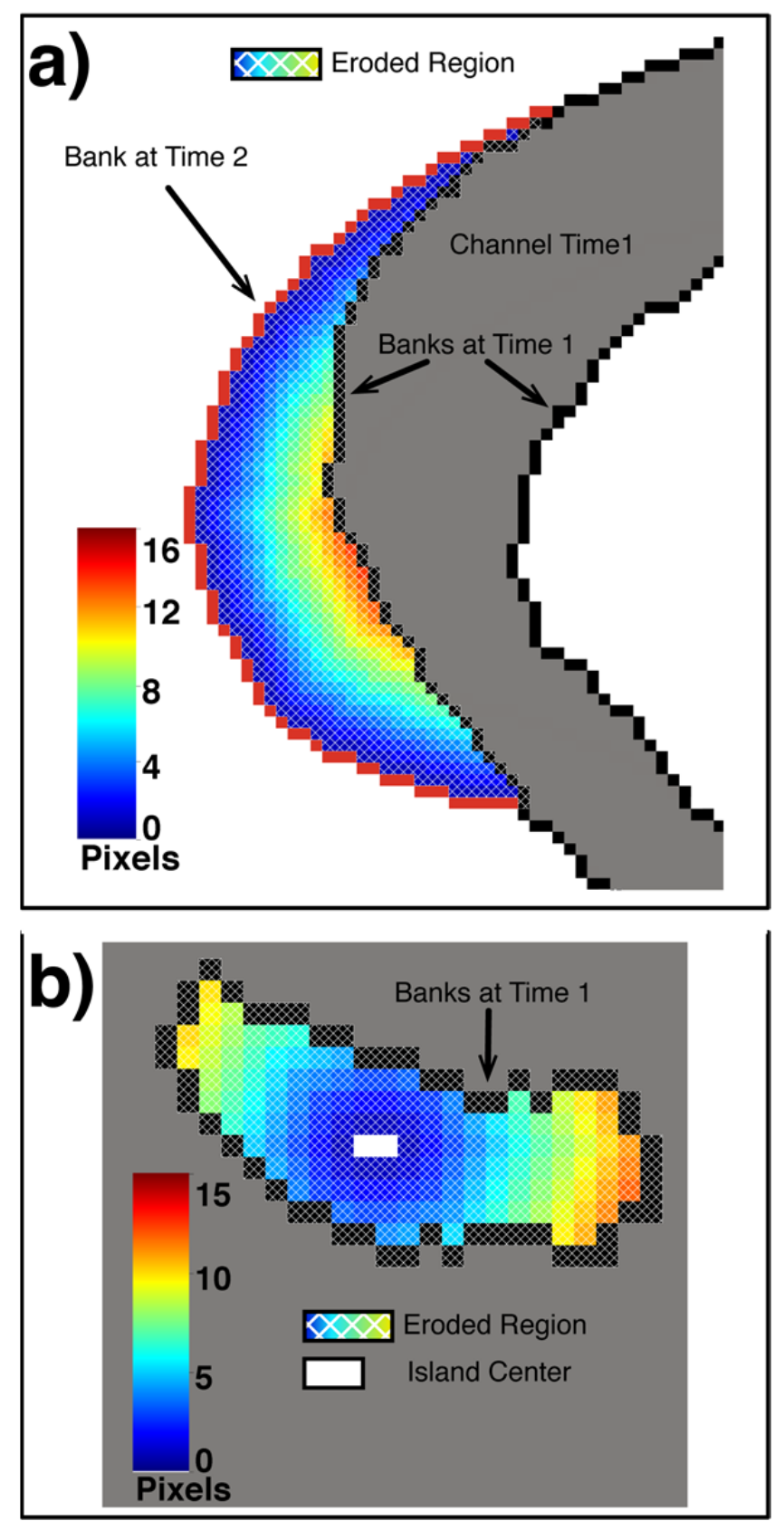
307 Figure 3: Graphical illustration of the determination of erosion distances (the method is identical 308 for accretion). a) A distance map (the colored pixels) is generated for each unique bank segment 309 from the Time 2 channel mask (red line) and intersected with the Time 1 bank pixels (black). A 310 linear rate of bank change is calculated by dividing the distance values by the time interval. b) 311 Measurement of erosion distances for an island that completely erodes between Time 1 and Time

312 2. The distance map is created from the pixel(s) in the interior of the island (white pixel in 313 colored region) that were furthest from any bank on the island perimeter at Time 1 . The distances 314 from bank pixels (black) to this interior point are determined by intersection with the distance 315 map.

SCREAM identifies the riverbank pixels by subtracting the input river masks from a copy

318 of the river mask dilated (expanded) by one pixel. This operation will create two bank segments

319 (a series of laterally adjacent pixels) on either side of a single-thread river with no islands, but

320 may delineate numerous unique bank segments for complex braided or anastomosing channels

321 with islands because our analyses include island margins as banks.

322 We assign erosion rates to bank pixel locations in the Time 1 raster and accretion to

323 pixels in the Time 2 raster because the reference bank pixels are only present at one time in the

324 case of mid-channel islands that completely erode or form between the two time intervals. In

325 these instances, SCREAM calculates change distances from the banks of the island to the pixel in

326 the interior of the island furthest from any of the bank pixels (Figure 3b).

\subsection{Width and bank aspect}

328 Channel width is commonly measured orthogonal to the mean downstream flow

329 direction, which is assumed to be approximately parallel to the inferred channel centerline

330 (Pavelsky \& Smith, 2008; Shields, Simon, \& Steffen, 2000). For a river channel with parallel

331 banks and a uniform width, this width will be the minimum distance between banks on opposite

332 sides of the river. In rivers with complex channel planforms the shortest distance between two

333 banks may significantly differ from the flow-normal cross sectional width (Figure 4). In order to

334 address complex river planforms, SCREAM uses both distance and bank orientation to 
336 parallel to the local bank orientation.

338 at each time interval. At each bank pixel (Figure 4 'target pixel'), SCREAM determines the

339 distance and angle to all the other bank pixels that fall within a subset of the river mask (Figure 4

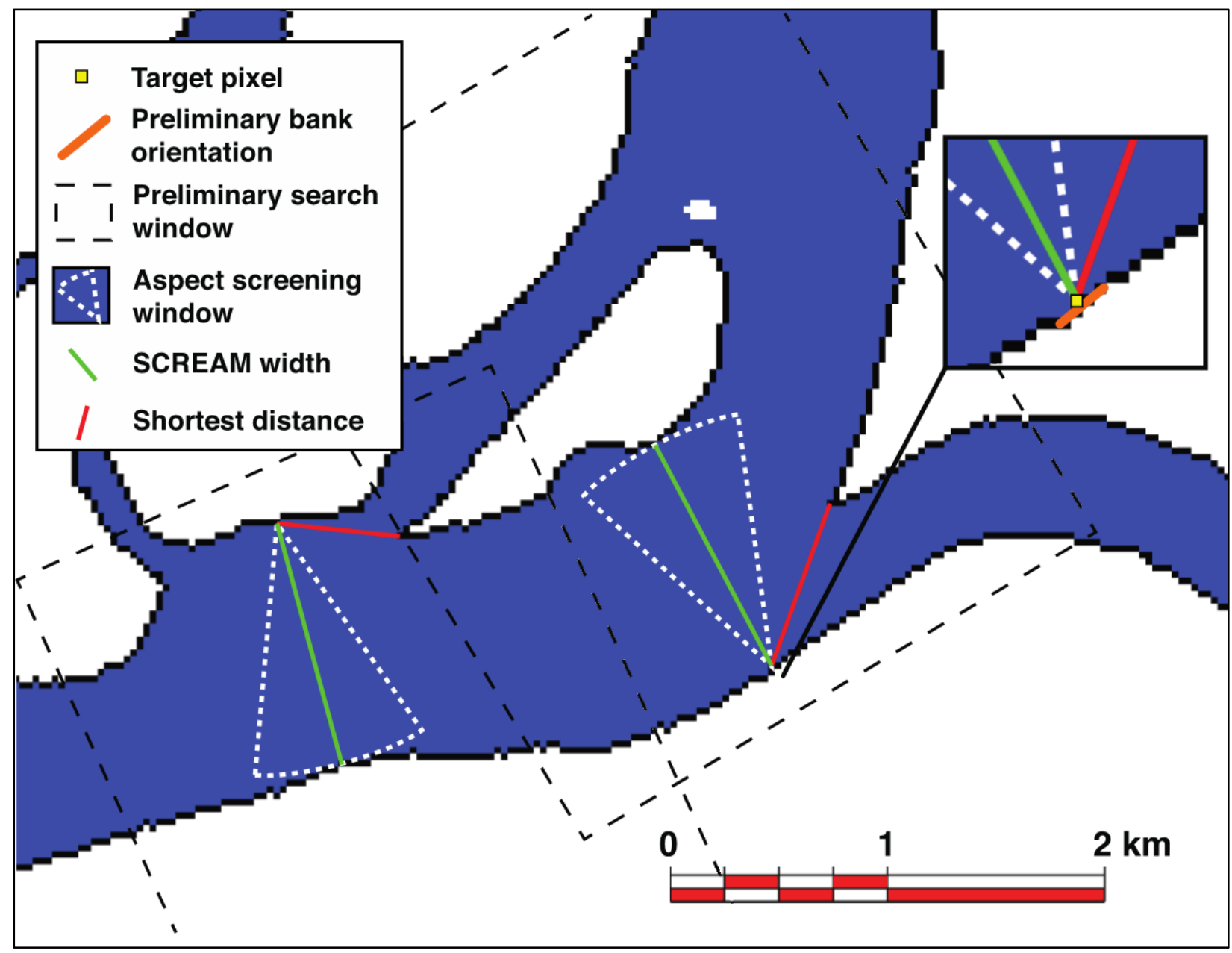

341 Figure 4: An illustration of the determination of channel width. The red lines represents the

342 shortest distance from a bank pixel to another bank line; the white dashed indicate the 40-degree 343 screening window; and the green lines are the shortest paths the screening window from a target 344 pixel (yellow) to the other bank.

346 'preliminary search window'). Any bank pixel in this window with an angle beyond that of the

347 'target' bank aspect \pm 20 degrees is eliminated from further consideration (Figure 4, 'aspect 
348 screening window'). We define the bank aspect as the orthogonal to the bank face (parallel to the

349 direction of bank retreat), which ranges from 0 to 359 degrees in accordance with a traditional

350 compass rose where 0 degrees represents north. The bank aspect used to set the screening

351 window is determined by fitting a line to five bank pixels centered on the 'target' pixel (Figure 4

352 'preliminary bank orientation'). From this subset of possible matching pixels, SCREAM selects

353 the pixel with the minimum distance from the 'target' pixel, and stores the distance and angle

354 between it and the 'target' pixel as the width and new bank aspect.

3552.4 Bank curvature and radius of curvature

356 The determination of bank aspects at all bank pixels allows for the calculation of the

357 change in bank orientation over user-specified distances along each bank segment. This change

358 in bank orientation divided by distance (radians/L) provides an estimate of bank curvature and its 359 inverse the radius of curvature (L/radians).

360 SCREAM calculates curvature at the channel banks, rather than along the centerline,

361 using an approach similar to that originally proposed by Nanson \& Hickin (1983). This approach

362 calculates curvature over two intervals centered on each bank pixel and then averages the two

363 values. We use default values of two and four local channel widths the length of the intervals,

364 following Nanson \& Hickin (1983), but the interval can also be defined by the user if desired. To

365 reduce noise in the curvature values, we first locally smooth the bank aspects using a Savitzky-

366 Golay filter following the approach of Fagherazzi, Gabet, \& Furbish (2004). We set the default

367 smoothing coefficients to remove high frequency and low amplitude noise resulting from the

368 non-continuous increments in bank aspects arising from the pixel-based representation of the

369 channel banks. Increasing or decreasing the distance interval over which the curvature is

370 calculated provides the ability to examine the influence of different scales of roughness on bank 
371 measurements of bank curvature and how these variations may relate to bank erosion (Darby et

372 al., 2010; Kean \& Smith, 2006a, b). The smoothing of the aspect values reduces the noise but

373 still preserves physical location of the bank pixels, in contrast to methods that smooth the

374 vertices (or pixel locations) of the line prior to calculating the curvature (e.g. Fagherazzi, Gabet,

375 \& Furbish, 2004; Güneralp \& Rhoads, 2008; Legleiter \& Kyriakidis, 2006).

376 SCREAM also assigns a sign value to each curvature measurement: positive for concave

377 (typically banks on the outside of a bend) and negative for convex (typically banks found on the

378 inside of a bend). SCREAM determines the sign of the curvature by finding the pixel that falls

379 midway along a line connecting the endpoints of the curvature interval and testing whether this

380 midpoint pixel falls inside or outside of the river channel. Segments with midpoints falling in the

381 river are assigned a positive value, indicating a concave bank. Although arbitrary, this sign

382 convention allows for a straightforward evaluation of patterns of erosion and accretion relative to

383 the inside and outside banks of river bends.

$384 \quad 2.5$ Centerline extraction, channel segmentation, and sinuosity

385 To provide spatial context to the measurements of channel change, width, and other

386 planview properties, SCREAM can segment the channel at regularly spaced, user-specified,

387 intervals (Figure 5). The spacing of the segment boundaries uses distances measured along the

388 channel centerline. For single-threaded channels, the centerline falls midway between the outer

389 banks. In a multi-threaded system, the centerline represents the midpoint between the two

390 outermost banks of the larger channel belt similar to the approach taken by the RivWidth

391 program (Pavelsky \& Smith, 2008). 
393 mask generated from the binary mask of the river channel where all of the islands have been

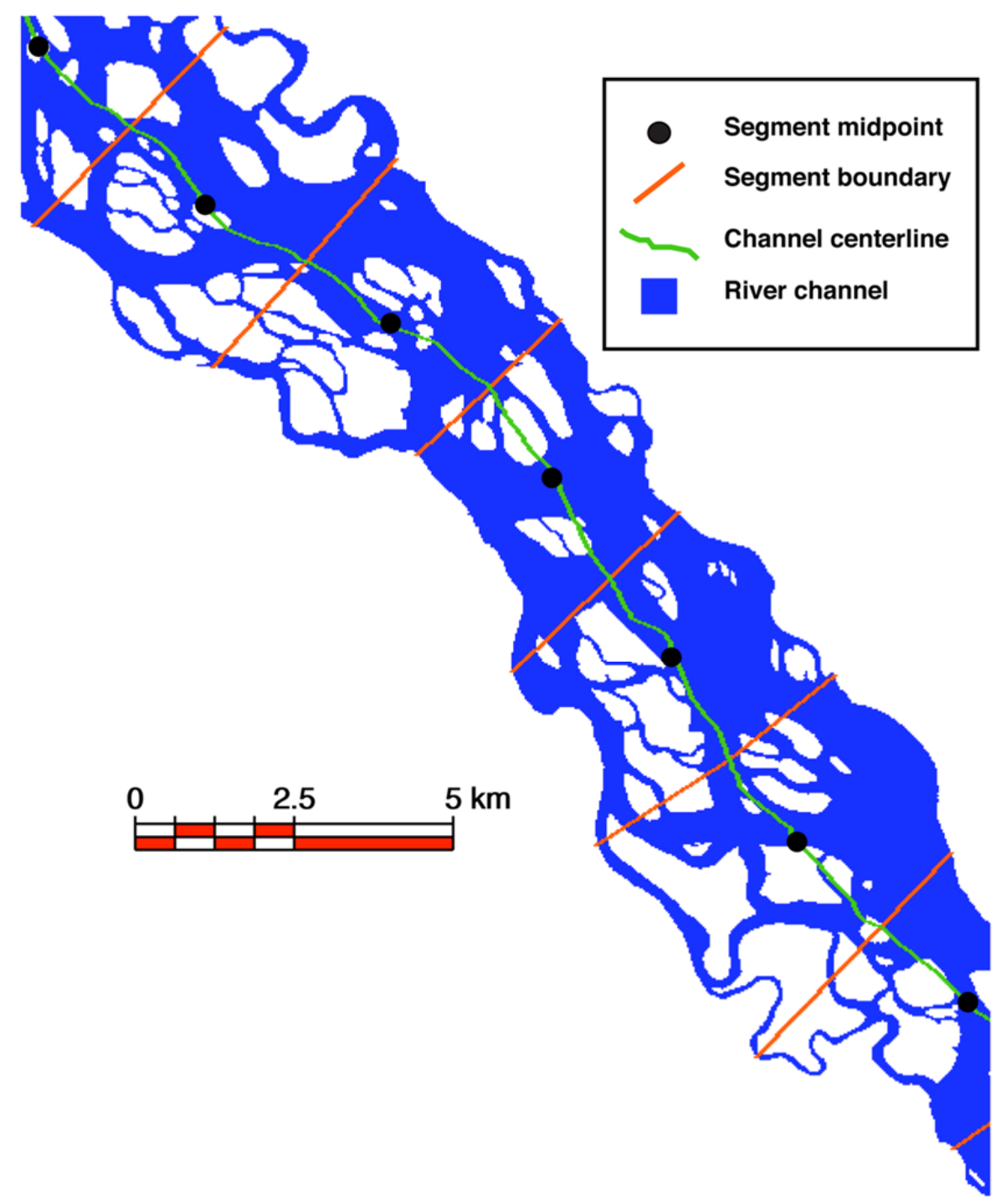

395 Figure 5: An example of a portion of the Yukon River binary channel mask showing 396 segmentation boundaries (red) and the centerline along which channel distances were calculated 397 (green). The sections boundaries are evenly spaced along the centerline, but do not have equal 398 areas. The black points mark the midpoint of the section on the centerline. 
399 removed so that the distances are measured from the outermost bank segments. The distances in

400 this mask are analogous to elevations in a digital elevation model (DEM) in which the highest

401 local elevations (found along the middle of the channel mask) form a drainage divide. A similar

402 approach is used skeletonization process adopted by others (Fisher, Bookhagen, \& Amos, 2013;

403 Graham, Reid, \& Rice, 2005; Pavelsky \& Smith, 2008). In addition to determining unique

404 channel centerlines at Times 1 and 2, SCREAM calculates an average centerline that lies

405 between the two time specific centerlines. This averaged centerline may be used as a common

406 reference for relating the spatial locations of river changes across multiple time periods.

407 The segmentation algorithm then uses the centerlines for each time interval to divide the

408 river raster into segments of equal length. Due to irregularities in the width between the

409 outermost boundaries in many rivers, these segments commonly do not have equal areas. On

410 some wide multi-threaded rivers with irregular outer boundaries, the use of lines orthogonal to

411 the channel centerline to segment the channel (e.g. Alber \& Piégay, 2011; Gangodagamage,

412 Barnes, \& Foufoula-Georgiou, 2007; Notebaert \& Piégay, 2013; Pavelsky \& Smith, 2008) led to

413 intersecting boundary lines that resulted in channel fragments isolated from the centerline.

414 Therefore, as an alternative to centerline orthogonals, SCREAM finds matching pairs of

415 centerline and boundary pixels that are both spaced at regular intervals and segments the channel

416 on lines connecting these pairs. To match a centerline pixel with a boundary pixel SCREAM

417 uses the distance maps of the filled channel and takes a steepest "walk" from the centerline to

418 each boundary. The paths of these steepest walks do not cross (avoiding isolated fragments) but

419 the spacing end points on the boundary may become irregularly spaced in very complex

420 channels. In these instances, if the spacing between adjacent boundary points is less than half the

421 specified segmentation interval SCREAM adjusts the location of the points to be evenly spaced 
422 between its neighboring boundary points. SCREAM then segments the channel along straight

423 lines connecting the paired boundary and centerline points. The relative downstream distance

424 and latitude and longitude of the midpoint of each segment is calculated and recorded.

425 Using this segmentation, the mean, median and standard deviation of erosion/accretion

426 rates, and channel widths may be calculated for each segment along the channel belt.

427 Segmentation also allows for the calculation of the total area of erosion/accretion in each

428 segment. Additionally, SCREAM calculates the total area of water and islands, the total length of

429 all banks and the length of island banks, and the total number of islands in each segment.

430 SCREAM calculates two measures of width for each segment: 1) the mean of all the

431 widths measured in a segment, and 2) the mean 'cumulative' width of all channel threads in a

432 segment. The 'cumulative' width is calculated by dividing the total area of river channel pixels in

433 the segment by the length of the segment. This metric provides an estimate of the average of

434 combined widths of all channel threads in any finite length of the river. Our cumulative width is

435 functionally equivalent to the "effective" width of Yamazaki et al. (2014), which is calculated by

436 dividing the total area of a segment (water and islands) by a representative width of the segment

437 and is also similar to the approach used by Church \& $\mathrm{Xu}(2015)$ to calculate reach averaged

438 channel widths.

439 SCREAM calculates the mean sinuosity for each segment from a continuous estimate of

440 sinuosity at every centerline pixel, using a moving window with a default value of 100 mean

441 channel widths (Snow, 1989). SCREAM calculates sinuosity by dividing the centerline distance

442 by the straightline Euclidian distance between the centerline endpoints within the window. In the

443 case of multi-threaded channels SCREAM reports the sinuosity of the larger channel belt and not

444 the sinuosity of individual channel threads within this belt. 
446 SCREAM produces two types of output: GeoTiff rasters and text files. Rasters may be

447 output for any of the pixel-based measurements: erosion/accretion rates, width, aspect, and

448 curvature, as well as, for the centerline pixels, associated downstream distance, and the

449 segmented channel. Text files store measurements for every bank pixel as well as for segments

450 along the channel, with measurements referenced to the relative downstream position and

451 latitude and longitude of the segment (Table 1).

\section{3. Results}

\section{$453 \quad 3.1$ SCREAM metrics}

454 SCREAM was tested on several Arctic rivers and a tropical river (Figure 6) that ranged in 455 width from 70 to $2000 \mathrm{~m}$ and varied in planform morphology from single-thread to braided.

456 Historical aerial photographs and satellite imagery with pixel resolutions ranging from 2 to $30 \mathrm{~m}$

457 were used for these analyses. When presented in raster space, the analyses provide a very

458 detailed view of river width, bank aspects, and the spatial patterns of erosion and accretion

459 (Figure 7), which may be compared at different time intervals for an individual river, used to

460 compare characteristics between river systems, or used to explore relationships between erosion

461 and accretion rates and river geometry. For example, the distribution of channel widths could be

462 used as an indicator of channel type, where a single-threaded river would have a normal

463 distribution of channel widths and a multi-threaded river would have a skewed distribution.

464 Figure 8 is illustrative of this concept, the largely single-threaded Strickland River, Papua New

465 Guinea has a nearly normal distribution and the complex, multi-threaded Yukon River, Alaska

466 has a highly skewed distribution of widths dominated by a large number of small channels. 
468 (Figure 9). On the Yukon River, plots of the distribution of bank aspect (Figure 9a) and the rates 469 of erosion (Figure 9b) show that banks facing to the southeast had the lowest distribution, but
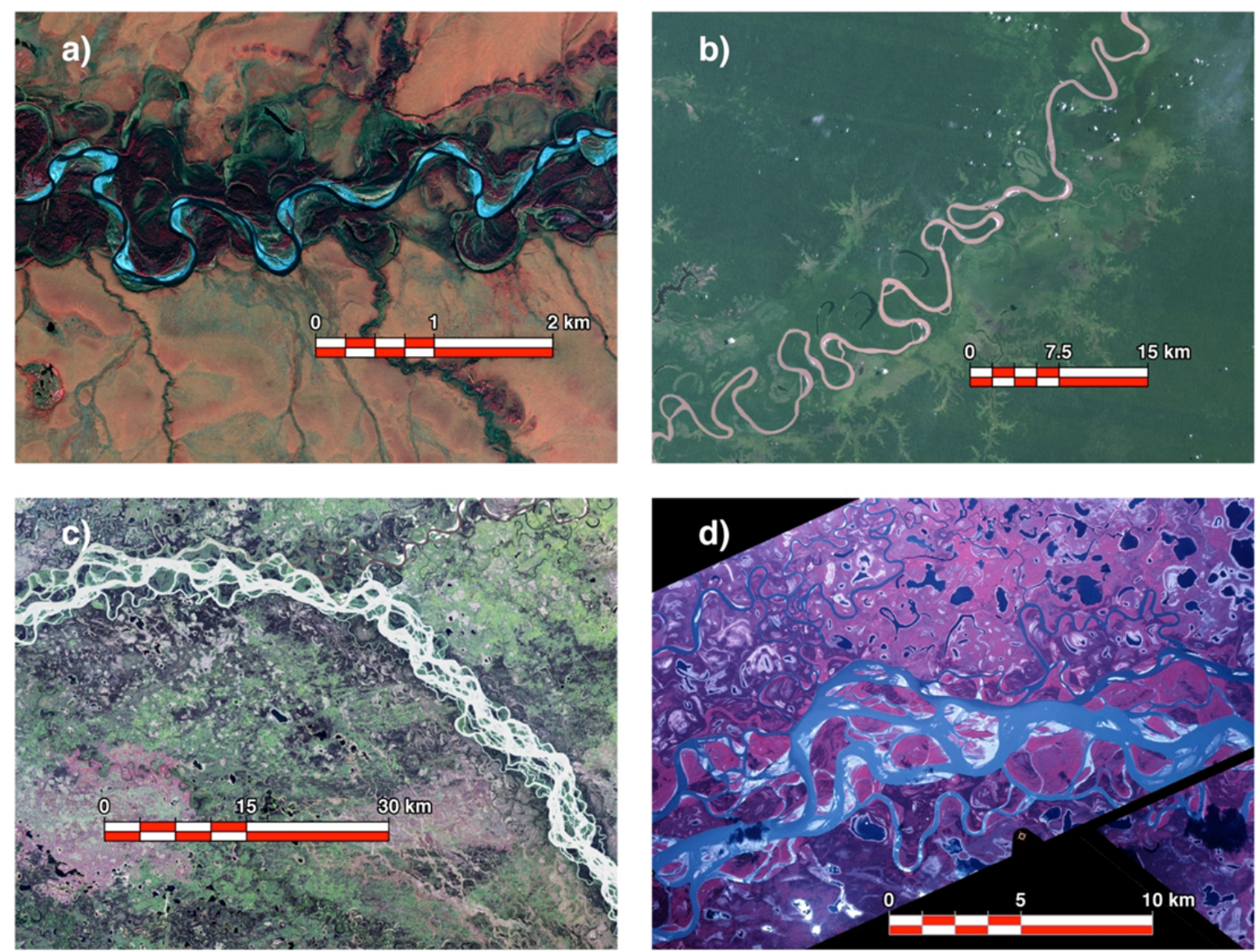

471 Figure 6: Images of portions of the river channels analyzed by SCREAM: a) the Selawik River 472 in northwest Alaska (September 24, 2009 Geoeye 2m false color image (near infrared, red, and 473 green bands)). b) the Strickland River, Papua New Guinea (March 26, 1993 Landsat $530 \mathrm{~m}$ 474 natural color (Bands 3,2,1), path 65, row 99). c) the Yukon River, Alaska (August 23, 2008 475 Landsat $530 \mathrm{~m}$ natural color composite (Bands 3, 2, 1), path 69, row 13) at 30m/pixel resolution 476 (image id: L5069013_01320080823). d) the Yukon River (1974 color infrared aerial photograph 477 scanned with a $2.5 \mathrm{~m} /$ pixel resolution). 


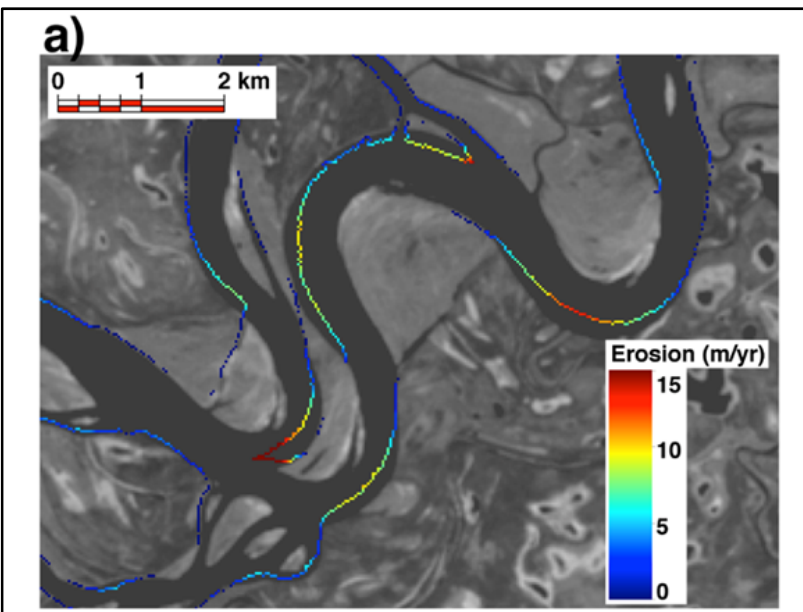

\section{c)}
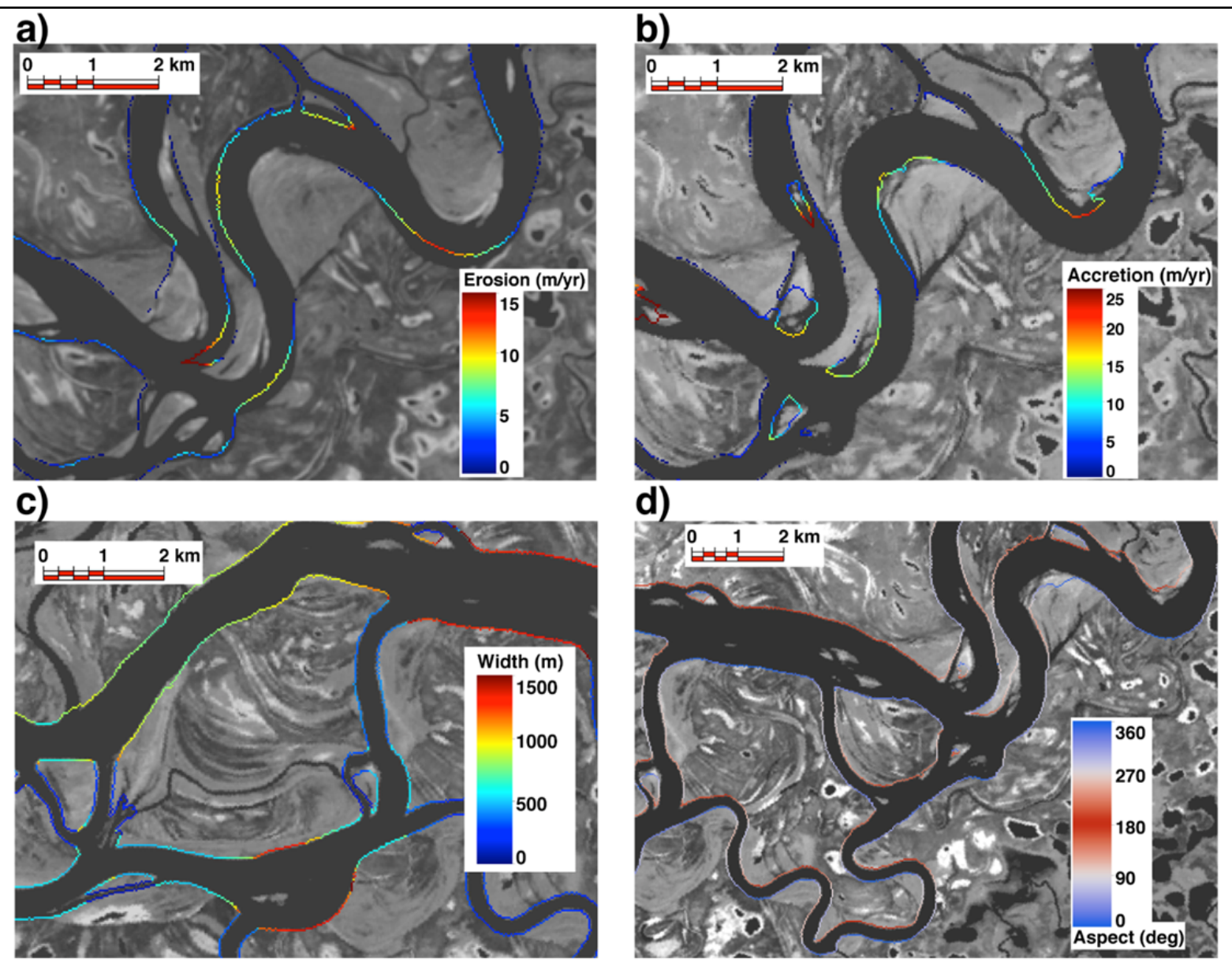

d)

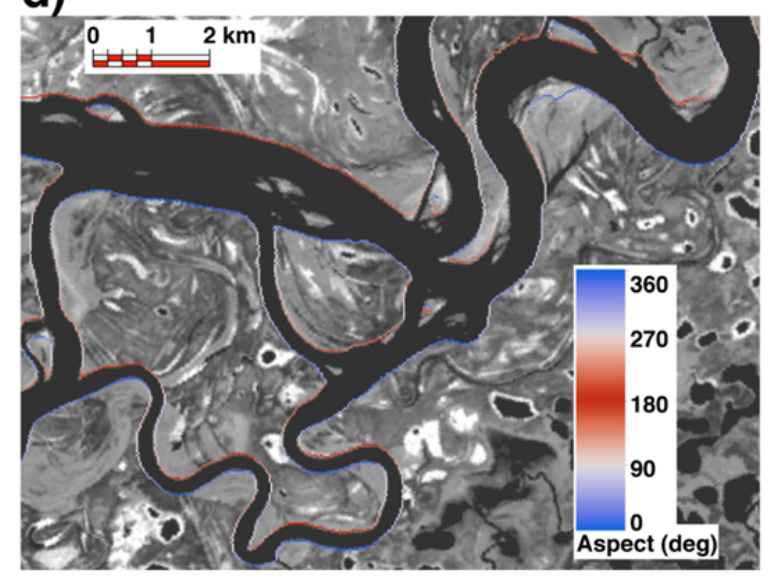

479 Figure 7: Raster-based output from SCREAM. a) Bank pixels showing erosion rates between 4801986 and 2008 of a small portion of the Yukon River. The bank pixel locations correspond to the 481 channel banks in 1986 the underlying panchromatic image was collected in 2008 by Landsat 5.

482 b) Accretion rates between 1986 and 2008 shown at the 2008 bank locations in scaled colors 483 overlain on the panchromatic image. c) Local channel widths for all 1986 bank pixels. d) Aspects 484 of the banks in 1986. Discharge measured at the Stevens Village gauge $90 \mathrm{~km}$ downstream 485 (USGS ID: 15453500) was 10,250 cubic meter per second (cms) on June 15, 1986 and 6,230 486 cms on August 30, 2008. The Landsat images were collected on June 15, 1986 (path 70, row 13) 487 488 for panels b-d and August 20, 2008 (path 70, row 13) for panel a. 


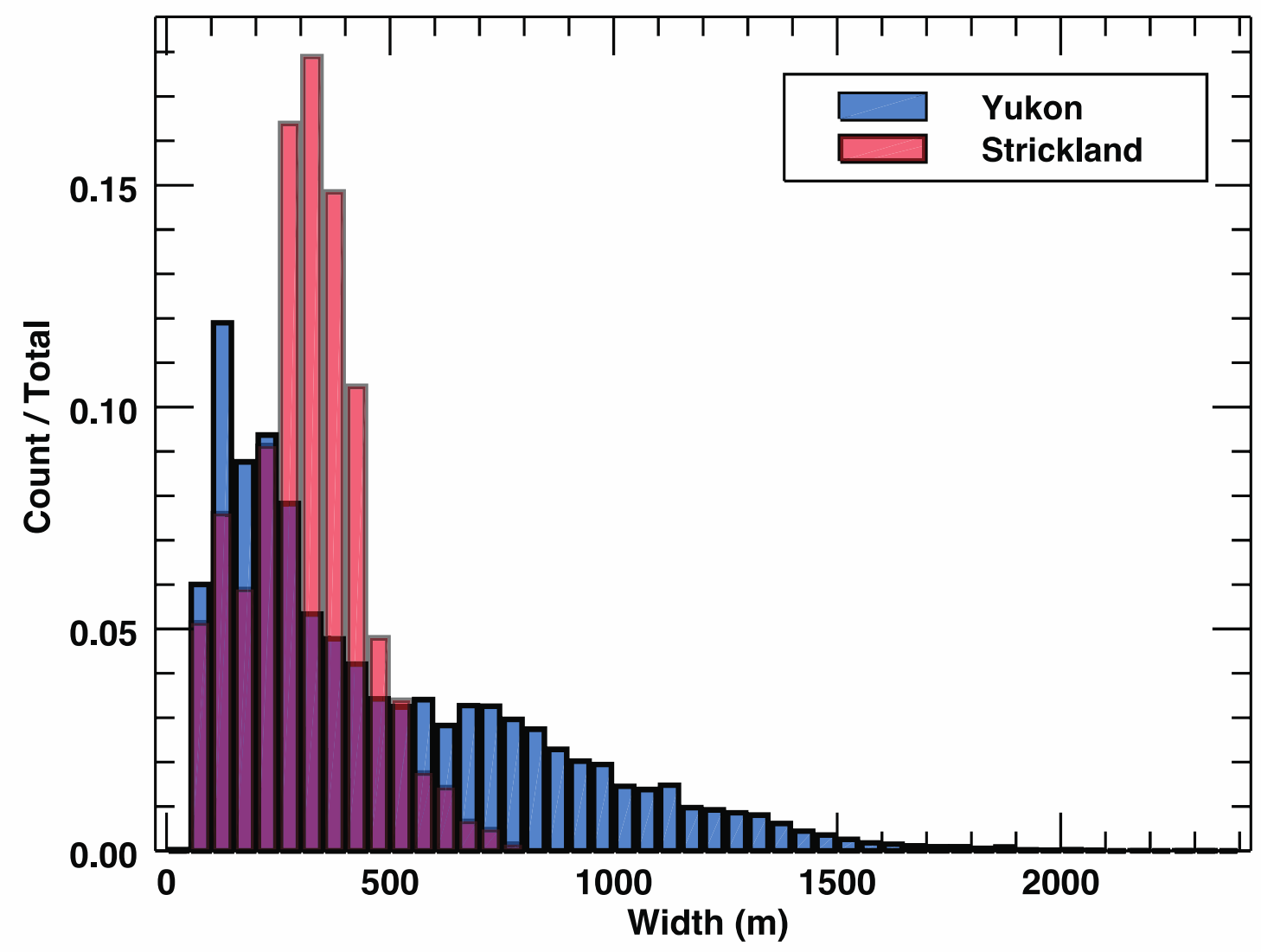

489

490 Figure 8: Histograms of local channel widths generated from the 1986 mask of the Yukon River 491 and the 1993 channel mask of the Strickland River.

492
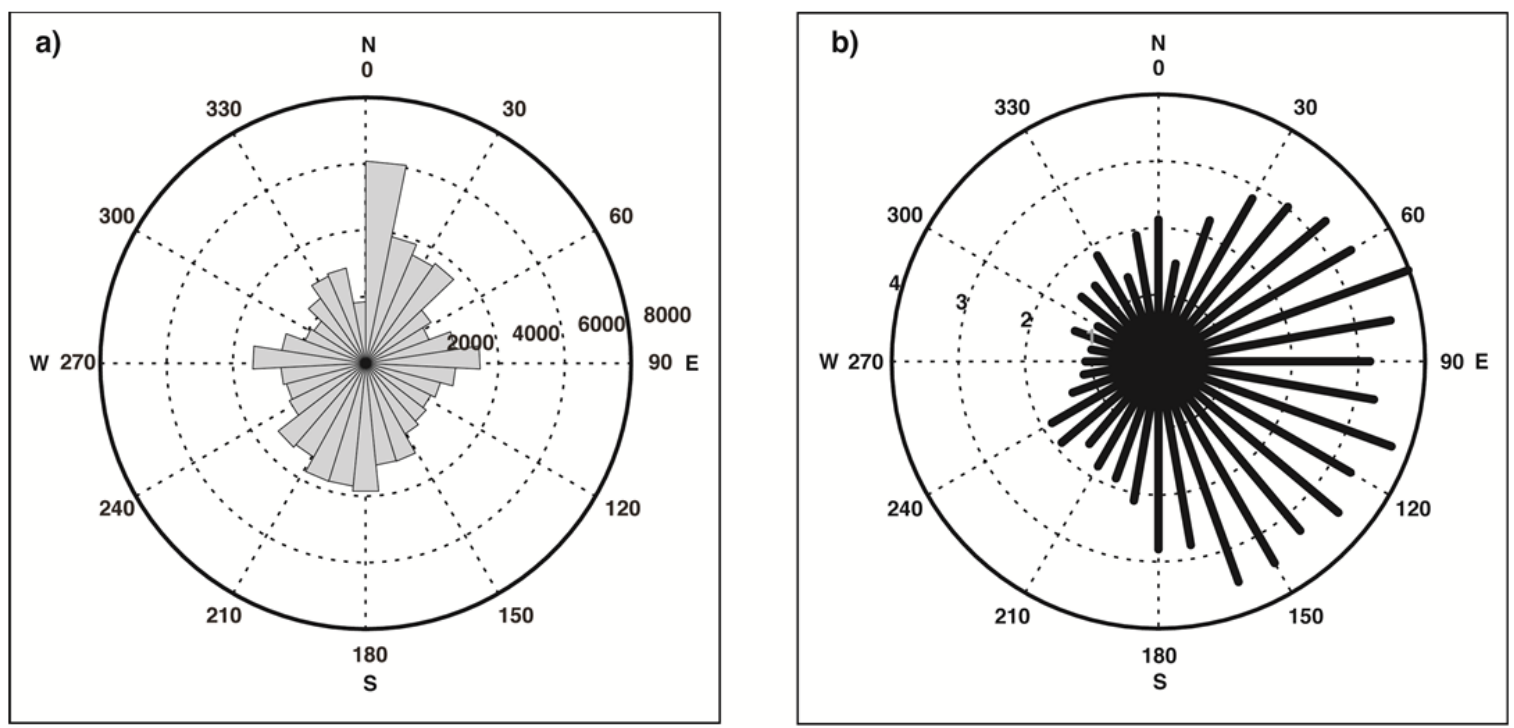
494 Figure 9: a) The distribution of all bank aspects for the 1986 mask of the Yukon River. The 495 dashed circles indicate the count of bank aspects within each aspect bin. b) Mean erosion rates 496 by bank aspect binned in 10 degree increments. The erosion rates were determined based on 497 changes in the river between 1986 and 1994. The dashed inner circles indicate erosion rates 498 ranging from 0 to $4 \mathrm{~m} / \mathrm{yr}$.

499 the highest rates of erosion. Such information has the potential to help identify river systems

500 where thermally controlled processes may be affected by solar radiation and influence erosion

501 rates. These systems include permafrost-dominated rivers and temperate rivers where freeze

502 thaw cycles may result in disaggregation of bank materials and increased net erosion (Lawler,

503 1986; Leopold, 1973; Pizzuto, 2009; Wolman, 1959; Wynn, Henderson, \& Vaughan, 2008;

504 Yumoto et al., 2006). Even in systems not sensitive to thermal dynamics, the analysis of erosion 505 rates by bank aspect may provide insight into the dominant directions of meander migration and 506 growth (Hooke, 1984).

507 Mean erosion and accretion rates and total area eroded/accreted with distance along a 508 river segment provides a spatial view of variations in river dynamics, facilitates the examination 509 of patterns of change over time, and allows for these changes to be related to sinuosity and other 510 channel planview attributes (e.g., number of islands, size of islands, and overall channel lengths 511 in a segment) in a manner similar to the analysis of the Amazon River by Mertes, Dunne, \&

512 Martinelli (1996). For example, Figure 10 shows erosion rates along the Yukon River between

5131986 and 2008. The total erosion and accretion areas can also be compared at discrete intervals

514 along the channel to identify regions of net sediment loss or gain (Figure 11). Combined with

515 cross-sectional data on the relative heights of eroding banks and accreting bars, this output can

516 be used to calculate the volume of sediment entering or leaving a river section due to the lateral 517 movement of the channel (Church, 2006; Lauer \& Parker, 2008a). Erosion rates can also be 518 scaled using measurements of channel width and radius of curvature Hooke (1980), allowing 
519 comparison of rates along a river and between river systems of vastly different sizes and channel

520 morphologies. The ability to examine the relationship between erosion rates and channel

521

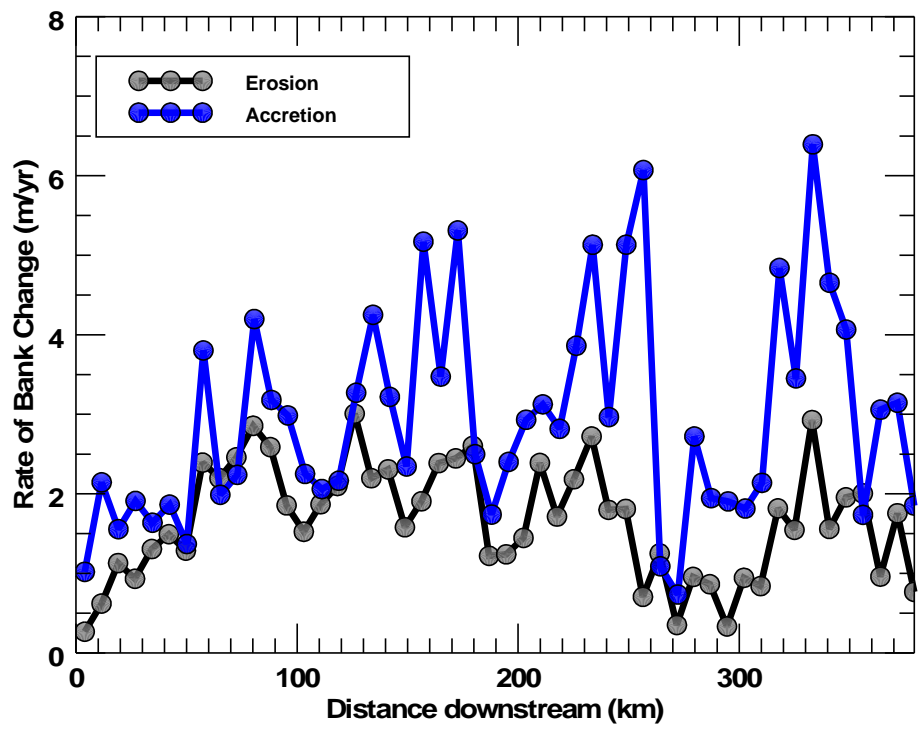

522

523 Figure 10: Erosion (a) and accretion (b) rates averaged at regularly spaced intervals along the 524 Yukon River for the time period of 1986 to 2008.

525

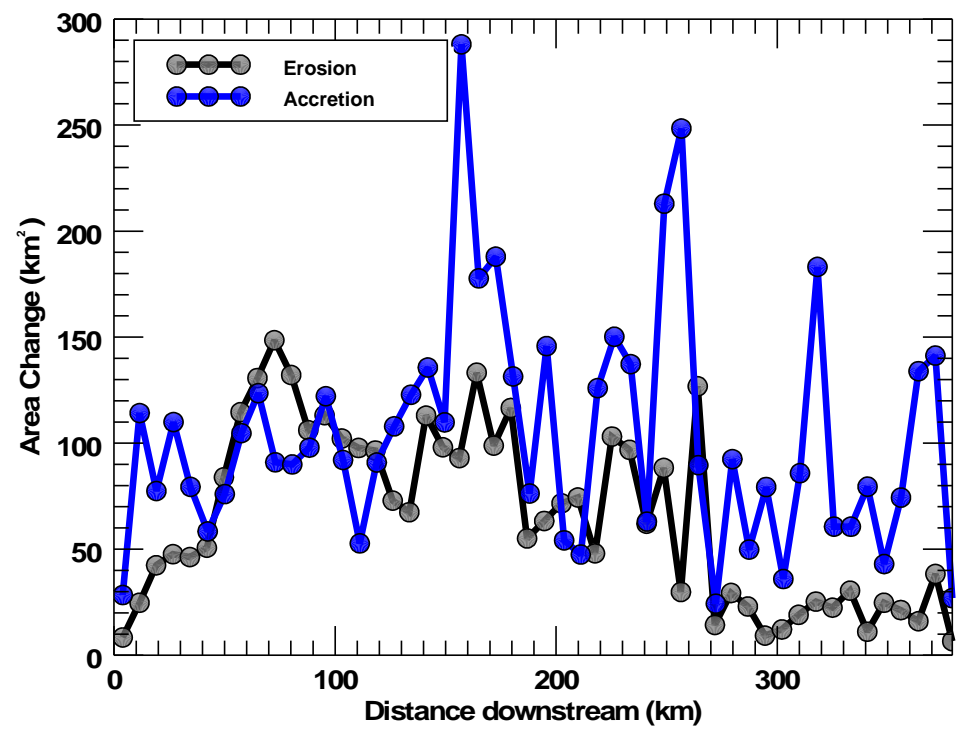


528 Figure 11: Total area of eroded and accreted floodplain for a portion of the Yukon River 529 between 1986 and 2008. The areas of accretion exceed erosion for a large portion of the reach, 530 an imbalance that reflects the infilling of the several large oxbows.

532 curvature at all bank pixels represents a significant opportunity to expand current datasets and

533 rigorously test the control of curvature on bank erosion rates.

534 SCREAM output allows for the examination of downstream trends in channel width with 535 two metrics: the average channel width within a segment of the channel belt; and the mean

536 cumulative width of all of the channel threads within a segment of the river (Figure 12). For a

537 single-threaded channel, the average width provides a measure of downstream trends in channel

538 width with less noise than measurements extracted from regularly spaced cross sections. The

539 mean cumulative width represents a potentially more useful estimate of the effective channel

540 cross-section of multi-threaded channels for hydrological modeling purposes (Allen \& Pavelsky,

541 2015; Pavelsky \& Smith, 2008; Yamazaki et al., 2014), because the presence of large numbers of

542 relatively small channels (Figure 8) will result in average widths significantly less than the

543 average cumulative width of all of the channels in a segment. 


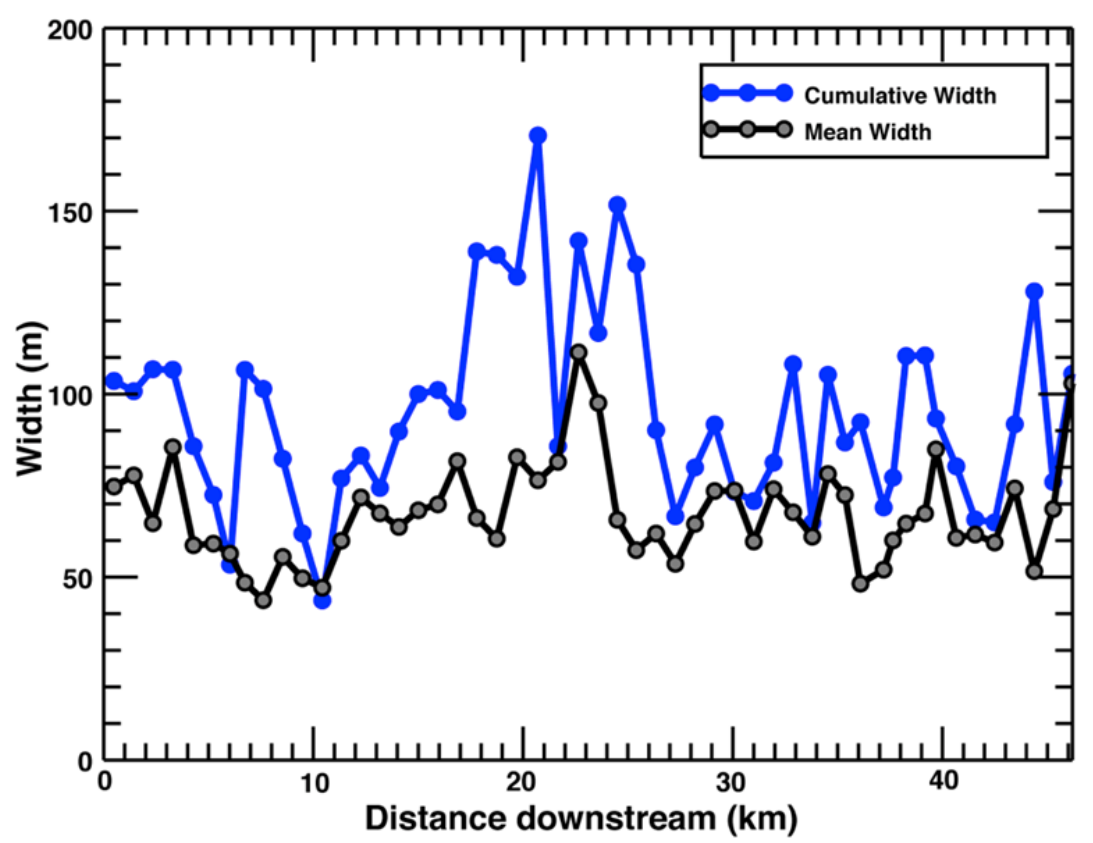

545 Figure 12: Measured widths for a portion of the Selawik River, Alaska from a 1981 aerial 546 photograph-derived channel mask. The mean channel width calculated at evenly spaced intervals

547 is shown in black and the average cumulative channel width of each segment is displayed in 548 blue. Where there is only a single channel thread in a segment the mean and cumulative widths 549 are equal.

550

\subsection{SCREAM Measurement Errors}

We quantified the error in measurements of erosion, local channel width, and bank

553 aspects to assess the accuracy of the metrics generated by SCREAM. It was assumed that the

554 error in accretion and erosion rates would be the same because they employed identical

555 measurement methodologies. Errors in river planview properties and change may arise in each

556 step of the image analysis and change detection process: image registration, feature

557 classification/extraction, and analysis of the binary rasters. These errors must be accounted for

558 and quantified (Downward, Gurnell, \& Brookes, 1994), in order to have confidence that

559 documented change in river systems are not artifacts of the analysis. Mount et al. (2003)

560 provided a detailed methodology for quantifying the errors associated with measurements of

561 channel bankfull width from sequences of aerial photography, and Mount \& Louis (2005) 
562 explained how to propagate errors from bankline delineation into measurements of centerline

563 migration rates. In these analyses, the source of error falls into two categories: 1) image

564 registration, and 2) feature identification and extraction. Errors can also arise during the

565 generation of the binary channel masks required by our analysis, but we do not attempt to

566 quantify this error because these masks may be generated by a number of different techniques.

567 Instead, we only quantify error arising from our methodology and the application of SCREAM to

568 these masks. The propagation of errors arising from image registration and feature identification

569 into metrics generated by SCREAM is discussed in Section 5 and Supplemental Materials.

570 Although image resolution will dictate whether a riverbank can be delineated (Congalton

$571 \&$ Green, 2008), the ability to accurately measure erosion, accretion and width is a function of

572 the size of the river being analyzed, rate of the channel change, and the time interval between

573 images (Grabowski, Surian, \& Gurnell, 2014; Mount et al., 2003). For example, images with

574 high spatial resolution would be needed to accurately measure small shifts in a slowly changing

575 river over a short time interval, but large shifts that are greater than the error in delineating the

576 boundaries of the same river could be detected with coarser-resolution imagery with longer time

577 periods between images.

578 Ideally, quantification of error would be based on the comparison of the SCREAM results

579 to a set of independently obtained ground-truthed values, but measurements of erosion were not

580 available for the time periods of images. Additionally, a field-based assessment of measurement

581 errors would require a subtraction of image registration and classification errors from the total

582 error in order to isolate the fraction of the error associated with the SCREAM analysis.

583 Therefore, our error assessment was performed by comparing SCREAM-generated results

584 against manual measurements made using the measurement tool in a GIS software package at a 
585 number of randomly selected locations along the river channels. The same analyst performed a 586 duplicate set of width and erosion measurements on the most complex river system on which 587 SCREAM was tested (the Yukon River) in order to quantify the human errors of interpretation 588 and precision inherent in these manually measured values. We believe these manual 589 comparisons to be a conservative estimate because they reduce judgment errors associated with 590 different analysts when there is ambiguity in deciding the correct measurement. Between 100 591 and 250 pixel locations were selected from each of three river systems that varied both in size 592 and planform morphology in order to measure local channel width, bank erosion, and aspect. The 593 imagery used for these systems ranged in resolution from 2 to $30 \mathrm{~m} /$ pixel.

594 Table 2 presents a summary of error assessments for SCREAM analyses; the erosion 595 values are linear distances in meters, not rates. A Wilcoxon rank sum test was performed to test 


\section{Table 2: Summary of Error Quantification}

\begin{tabular}{|c|c|c|c|c|c|c|c|c|c|c|c|c|}
\hline $\begin{array}{l}\begin{array}{l}\text { River } \\
\text { (dates) }\end{array} \\
\text { (dates }\end{array}$ & Measurement & $\begin{array}{c}\text { Image } \\
\text { Resolution } \\
\text { (m/pixel) }\end{array}$ & $\begin{array}{c}\text { Mean } \\
\text { Erosion } \\
(\mathbf{m})\end{array}$ & $\begin{array}{c}\text { Max } \\
\text { Erosion } \\
(\mathbf{m})\end{array}$ & $\begin{array}{c}\text { Mean } \\
\text { Width } \\
(\mathbf{m})\end{array}$ & $\begin{array}{c}\text { Max } \\
\text { Width } \\
\text { (m) }\end{array}$ & $\mathbf{n}$ & Wilcoxon $^{1}$ & $\mathbf{p}^{2}$ & $\begin{array}{c}\text { Nash- } \\
\text { Sutcliffe } \\
\text { EC }^{3}\end{array}$ & $\begin{array}{c}\text { SE of } \\
\text { RMSE }^{4}\end{array}$ & $\begin{array}{c}\text { SE } \\
\text { (pix) }\end{array}$ \\
\hline Yukon & & 30 & 39 & 932 & 482 & 2327 & -- & -- & -- & -- & -- & -- \\
\hline \multirow[t]{3}{*}{ (1986-2008) } & Erosion $(\mathrm{m})$ & -- & -- & -- & -- & -- & 250 & $\mathrm{~N}$ & 0.86 & 0.99 & 0.67 & 0.02 \\
\hline & Local Width (m) & -- & -- & -- & -- & -- & 250 & $\mathrm{~N}$ & 0.85 & 0.76 & 12.14 & 0.4 \\
\hline & Aspect (deg) & -- & -- & -- & -- & -- & 250 & $\mathrm{~N}$ & 0.77 & 0.96 & 1.27 & NA \\
\hline Yukon & $\begin{array}{l}\text { Comparison of manual } \\
\text { measurements }\end{array}$ & 30 & -- & -- & -- & -- & -- & -- & -- & -- & -- & -- \\
\hline \multirow[t]{2}{*}{ (1986-2008) } & Erosion (m) & -- & -- & -- & -- & -- & 250 & $\mathrm{~N}$ & 0.68 & 0.99 & 0.52 & 0.02 \\
\hline & Local Width (m) & -- & -- & -- & -- & -- & 250 & $\mathrm{~N}$ & 0.82 & 0.87 & 8.89 & 0.30 \\
\hline Yukon & & 2.5 & 18 & 543 & 354 & 2077 & -- & -- & -- & -- & -- & -- \\
\hline \multirow{2}{*}{ (1974-1981) } & Erosion (m) & -- & -- & -- & -- & -- & 195 & $\mathrm{~N}$ & 0.89 & 1.00 & 0.06 & 0.03 \\
\hline & Local Width (m) & -- & -- & -- & -- & -- & 195 & $\mathrm{~N}$ & 0.98 & 0.98 & 3.57 & 1.40 \\
\hline Selawik & & 2.0 & 21 & 160 & 66 & 316 & -- & -- & -- & -- & -- & -- \\
\hline \multirow[t]{4}{*}{ (1981-2009) } & Erosion $(\mathrm{m})$ & -- & -- & -- & -- & -- & 100 & $\mathrm{~N}$ & 0.75 & 0.63 & 1.2 & 0.6 \\
\hline & Local Width (m) & -- & -- & -- & -- & -- & 100 & $\mathrm{~N}$ & 0.97 & 0.93 & 1.44 & 0.72 \\
\hline & Cumulative Width (m) & -- & -- & -- & -- & -- & 219 & $\mathrm{~N}$ & 0.86 & 0.06 & 0.85 & 0.42 \\
\hline & Aspect (deg) & -- & -- & -- & -- & -- & 82 & $\mathrm{~N}$ & 0.84 & 0.98 & 1.7 & NA \\
\hline Strickland & & 30 & 57.4 & 636 & 336 & 826 & -- & -- & -- & -- & -- & -- \\
\hline \multirow[t]{4}{*}{ (1993-2007) } & Erosion $(\mathrm{m})$ & -- & -- & -- & -- & -- & 100 & $\mathrm{~N}$ & 0.97 & 0.99 & 0.65 & 0.02 \\
\hline & Local Width (m) & -- & -- & -- & -- & -- & 100 & $\mathrm{~N}$ & 0.69 & 0.98 & 1.61 & 0.05 \\
\hline & Cumulative Width (m) & -- & -- & -- & -- & -- & 284 & $\mathrm{Y}$ & $<1 \mathrm{e}^{-4}$ & 0.86 & 1.38 & 0.05 \\
\hline & Aspect (deg) & -- & -- & -- & -- & -- & 100 & $\mathrm{~N}$ & 0.74 & 0.99 & 0.64 & NA \\
\hline \multirow[t]{3}{*}{$\begin{array}{l}\text { All Systems } \\
\text { (Pixels) }\end{array}$} & & & & & & & & & & & & \\
\hline & Erosion (pix) & -- & -- & -- & -- & -- & 645 & $\mathrm{~N}$ & 0.93 & 0.86 & -- & 0.09 \\
\hline & Local Width (pix) & -- & -- & -- & -- & -- & 645 & $\mathrm{~N}$ & 0.98 & 0.99 & -- & 0.47 \\
\hline
\end{tabular}

597 Notes: all erosion values are linear distances, not rates

$598 \quad \mathrm{n}$ - number of measurements in error assessment

$599 \quad 1$ - Wilcoxon rank sum test, reject null hypothesis at $5 \%$ significance $(\mathrm{N}-$ no, $\mathrm{Y}-\mathrm{Yes})$

$600 \quad 2-$ p-value for Wilcoxon test

6013 - Efficiency coefficient

$6024-$ Standard Error (SE) of Root Mean Square Error (RMSE) 
603 whether each set of SCREAM-derived values and corresponding manual measurements were

604 from continuous distributions with equal medians (Zar, 1999), because the distributions of many

605 of the measurement sets were right skewed and non-normal. The Wilcoxon tests only rejected

606 the null hypothesis for the cumulative widths for the Strickland River, indicating that all of the

607 manual and SCREAM-derived measurements were comparable except in this isolated case.

608 We also calculated a Nash-Sutcliffe efficiency coefficient (Nash \& Sutcliffe, 1970) for

609 each set of measurements (Table 2). The efficiency coefficient was developed for hydrological

610 modeling and results in values ranging from $-\infty$ to 1 , where a value of 1 indicates a perfect

611 agreement between model predictions and observed data. Nash-Sutcliffe coefficients of

612 efficiency for all measurements, excluding the cumulative widths, were greater than 0.63 , with 9

613 of the 13 comparisons having values greater than 0.95 , suggesting that SCREAM-generated

614 measurements agree well with those made manually.

615 Finally, for each set of measurements, we report the standard error (SE) of the root mean

616 square error (RMSE) of the differences between the two methods, because the SE is a more

617 appropriate measure than the RMSE for evaluating and propagating errors in river change

618 studies, although it is less conservative (Mount \& Louis, 2005). Quantitatively, the SEs confirm

619 that the measurement errors associated with our analysis were low. SEs for erosion distance

620 ranged from 0.06 to $1.2 \mathrm{~m}$ ( 0.02 to 0.6 pixels), while SEs in local width ranged from 1.4 to 12.1

$621 \mathrm{~m}(0.05$ to 1.4 pixels). The larger errors associated with the width measurements do not increase

622 with the magnitude of the measurements; there was a very weak relationship, at most, between

623 the magnitude of the measurement and the size of the error, suggesting that the error in these

624 measurements may be propagated as a fixed value rather than as a percent of the measurement

625 itself. SE values for the manual measurements on the Yukon River (1986-2008) were within 
$62630 \%$ of those for SCREAM, suggesting a significant portion of the SCREAM errors may arise

627 from the inherent uncertainty in the manual measurement methodology. Overall, the low

628 standard errors, the results of the statistical tests, and the errors associated with the manual

629 measurements all indicate that SCREAM-generated width and erosion measurements do not

630 differ significantly from those obtained by manual measurements.

631 Low SEs of measurements of bank aspects (0.64 to 1.7 degrees) on the Yukon (1986-

632 2008), Selawik, and Strickland Rivers suggest that SCREAM does well at measuring the

633 riverbank orientation. Manual evaluation of curvature and radius of curvature proved more

634 challenging and could only be performed in a qualitative manner. Radii determined by drawing

635 circles superimposed onto channel bends (Lagasse et al., 2004) gave values consistent with the

636 range calculated by SCREAM. The placement and fit of circles, however, can be quite subjective

637 in general (Hooke, 1984), and has been noted to be problematic on compound and sharp bends

638 (Hooke \& Yorke, 2010). Section 4 presents a comparison of SCREAM's curvature values with

639 the algorithms developed by Legleiter \& Kyriakidis (2006).

640 Manual measurements of the cumulative width on a multi-threaded river would require

641 an analyst to measure each individual channel width and then sum these widths along a cross

642 section that bisects the network of channels. Obtaining enough cumulative measurements to

643 calculate a robust average width along a section can be very labor intensive and time consuming.

644 Due to this limitation we only evaluated cumulative widths on single-threaded sections of rivers

645 and a simple synthetic multi-thread channel that had straight segments with 1 to 4 channels of

646 varying sizes.

647 Of the river systems tested, the Strickland and Selawik rivers had large numbers of

648 segments with only one channel thread, 284 out of 428 and 219 out of 422, respectively. The SEs 
649 in cumulative width for both systems was low: $1.38 \mathrm{~m}$ ( 0.05 pixels) for the Strickland and $0.85 \mathrm{~m}$

650 (0.42 pixels) for the Selawik. These errors, however, were not randomly distributed. The

651 cumulative width was systematically smaller than the mean width by 6 to $7 \%$ which appears to

652 have resulted from an overestimation of segment length when distances were calculated along

653 the pixel-based delineation of the segment's centerline. Despite accounting for the difference in

654 distance between diagonally $(\sqrt{2})$ and orthogonally (1) connected pixels, centerline distances

655 typically varied from manually measured distances by $\sim 6 \%$; an error consistent with those

656 reported from other studies calculating streamline distances from raster-based data (da Paz et al.,

657 2008; Paz \& Collischonn, 2007).

$658 \quad 3.3$ Comparison of methodologies

659 The large diversity of methodologies for quantifying river planview change and

660 characteristics renders comparison of metrics between studies challenging, because each was

661 developed for different applications and is reported in different formats (Table 1). Rather than

662 judge the relative accuracy or utility of one method over another, we provide a comparison of

663 rate of bank erosion inferred from lateral migration made by PST (ArcGIS-based Planform

664 Statistics Toolbox (Aalto, Lauer, \& Dietrich, 2008), available at:

$665 \mathrm{http} / /$ www.nced.umn.edu/content/stream-restoration-toolbox), measurements of bank curvature

666 using the Legleiter curvature code (LCC; Legleiter \& Kyriakidis (2006), and mean cumulative

667 width calculated by RivWidth (Pavelsky \& Smith, 2008) to comparable measurements using

668 SCREAM. A natural river channel with a range of planform patterns was used for the analysis of

669 mean cumulative width, while a simple synthetic single-threaded test channel was created with a

670 periodic function with constant width (Figure 13) to assess the rate of bank erosion and bank 


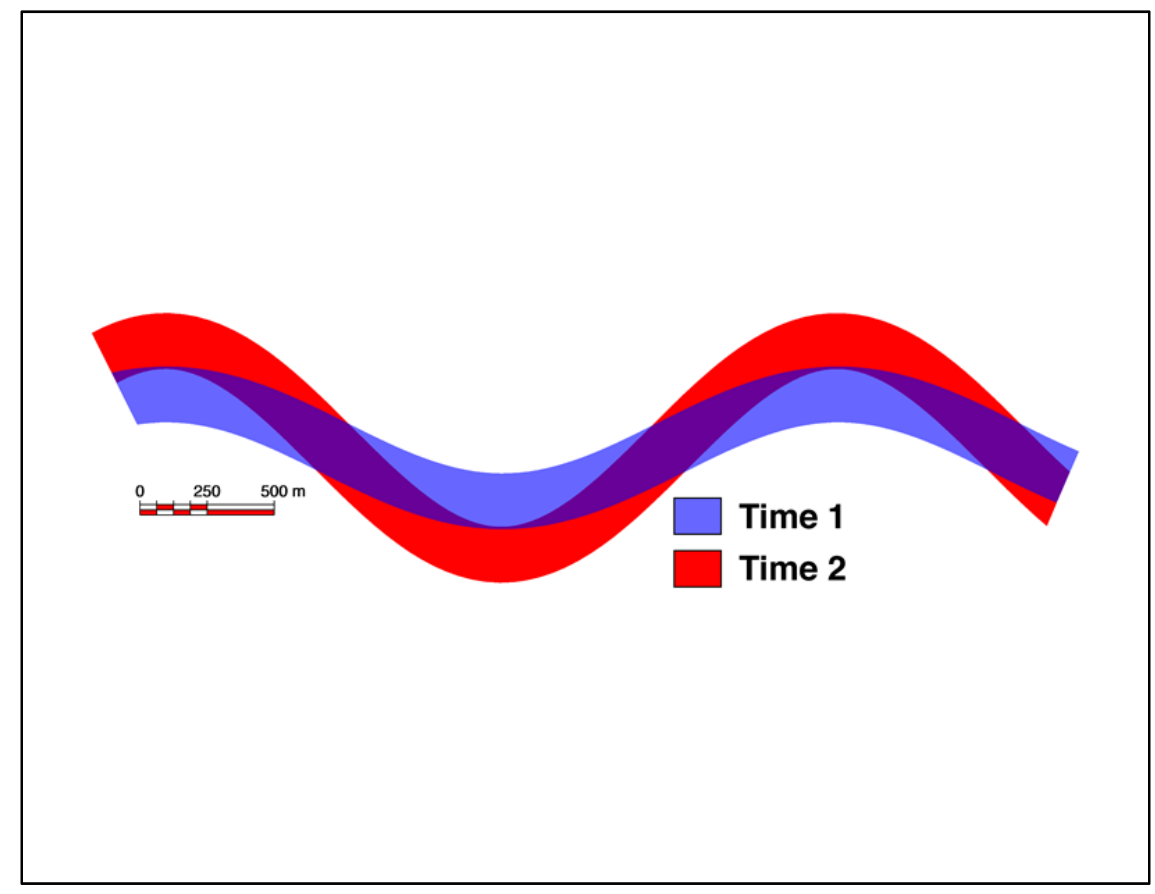

672 Figure 13: Synthetic river channel generated using a periodic function with constant width 673

674 curvature because each methodology had a different measurement technique that could not be

675 readily compared on a natural system.

676 3.3.1 Rate of bank erosion

677 PST does not directly measure rate of bank erosion; it measures channel migration rates,

678 which can be used to infer rates of bank erosion in the controlled case of our test channel.

679 Specifically, erosion and accretion are equal along the channel and match centerline migration

680 (refer to Figures 1a and 13). PST derives representative centerlines for two time intervals from

681 vector-based representations of channel banks, and determines centerline migration by

682 measuring the displacement in the location of the centerlines.

683 We applied the PST to the test channel and recorded migration rates at intervals of $25 \mathrm{~m}$

684 and $100 \mathrm{~m}$ intervals along the channel and plotted them against $100 \mathrm{~m}$ averages of the continuous

685 SCREAM erosion measurements (Figure 14). A direct one to one comparison of rates between 


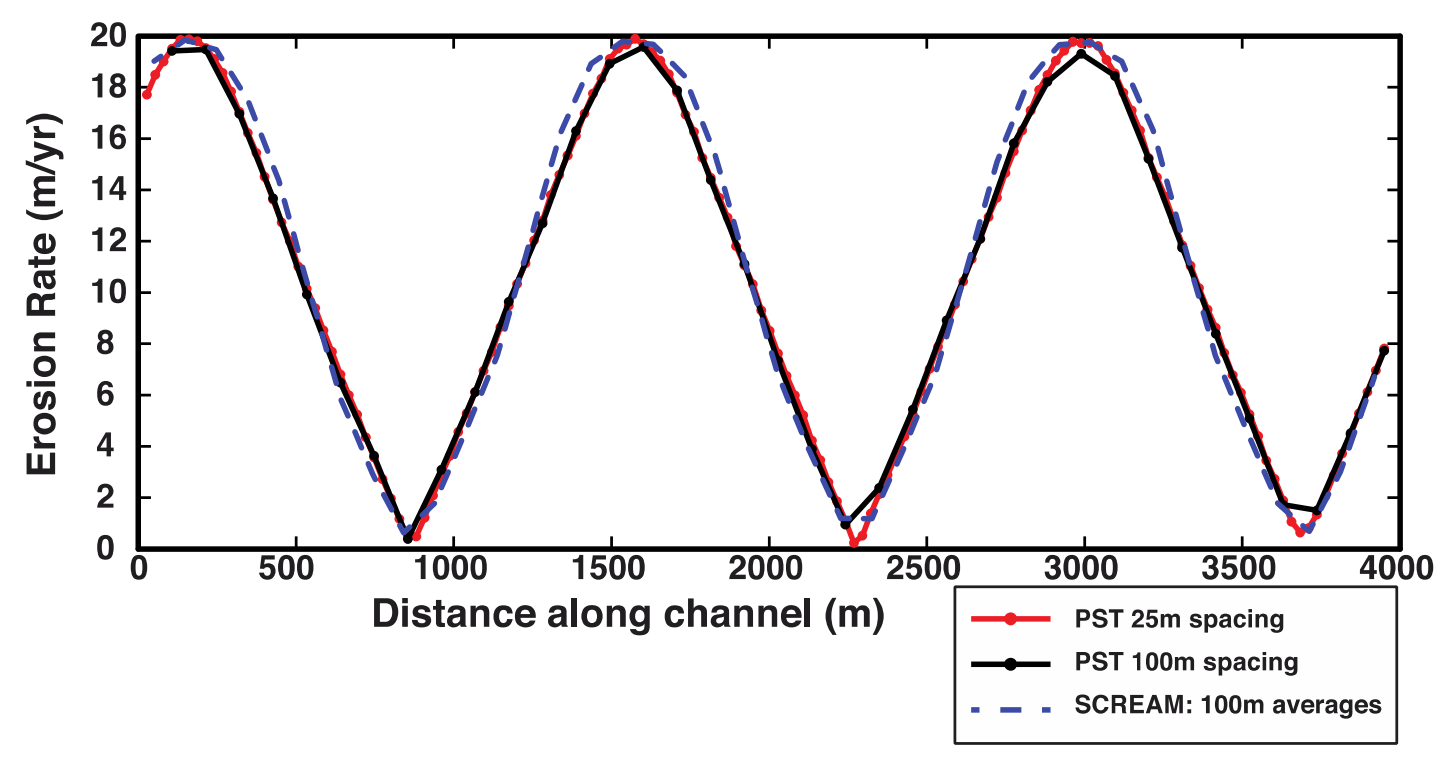

687 Figure 14: A comparison SCREAM erosion rates for synthetic channel (Figure 13) averaged 688 over $100 \mathrm{~m}$ long segments (blue line) against lateral migration rates determined using the 689 Planform Statistics Toolbox (Aalto, Lauer, \& Dietrich, 2008) calculated at evenly spaced 690 intervals of 25 (red line) and $100 \mathrm{~m}$ (black line) along the channel.

692 the two methods was not possible because PST provides discrete measurements at fixed intervals 693 along the centerline while SCREAM's values represent the average erosion rate of all the bank

694 locations within each $100 \mathrm{~m}$ long interval. In instances where channel migration directly reflects

695 bank erosion, SCREAM's bank erosion rates appear to be directly comparable to migration rates

696 determined using PST's centerline-based methodology (Figure 14).

697 3.3.2 Bank curvature

698 We evaluated SCREAM's estimates of bank curvature by comparing curvature from the 699 upper bank in the Time 1 synthetic channel (Figure 13) to curvatures calculated from the second 700 derivative of a spline generated from a digitized line segment (Fagherazzi, Gabet, \& Furbish,

701 2004; Güneralp \& Rhoads, 2008; Legleiter \& Kyriakidis, 2006) as represented by LCC. In its

702 creation of a spline, LCC produces spatial values that are not directly comparable to raster

703 locations, requiring a transformation of the LCC curvature values into raster-space by 
704 performing a piecewise linear interpolation of endpoints, curvature maximums, and zero crossing

705 points matched to the SCREAM output. Figure 15a compares SCREAM curvatures calculated

706 over bank distance intervals of 4,2 , and $1 / 2$ channel widths to bank curvature calculated using the

707 LCC smoothed 5 times with a 1-channel width wide filtering window and fit with a $3^{\text {rd }}$ order

708 polynomial. As the length of the interval over which SCREAM calculates the curvature

709 decreases, the peak SCREAM curvature values approach the LCC-based values (Figure 15b).

710 Even though the LCC method allows for variation in the size of the smoothing window, the

711 method always determines curvature over an infinitely small distance.

a)

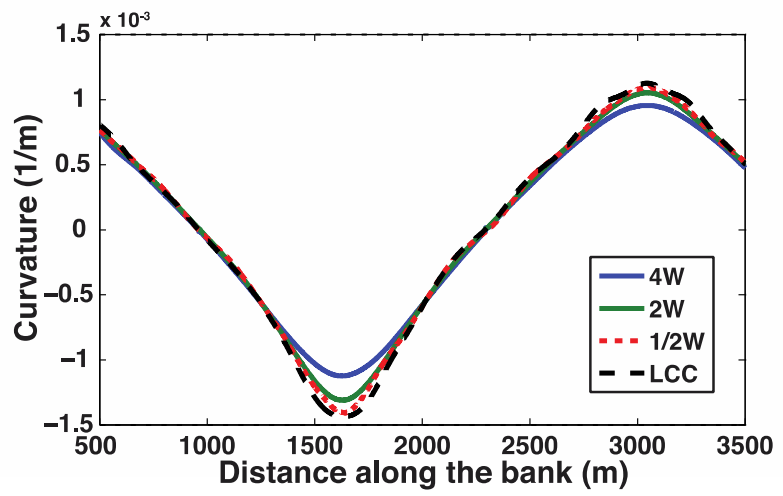

b)

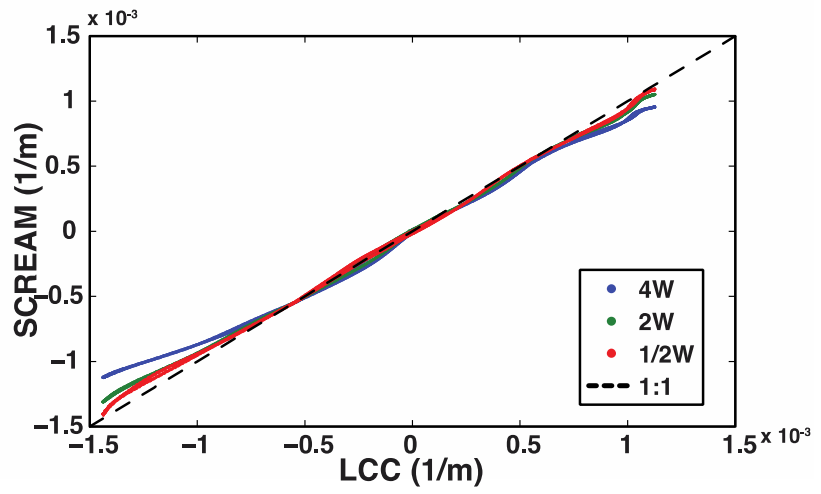

713 Figure 15: Comparison of bank curvature values from SCREAM to curvature determined using
714 LCC (Legleiter \& Kyriakidis, 2006). The comparison was performed on the top bank in the Time 1 synthetic raster (Figure 13). a) The black lines show the curvature values obtained using smoothed data, LCC, and a $3^{\text {rd }}$ order polynomial to fit a line to the bank pixels and the data was smoothed 5 times prior to fitting the polynomial. The SCREAM calculated curvature values were obtained using distance intervals of $1 / 2,2$, and 4 channel widths (red, green, and blue lines respectively). b) a scatter plot showing SCREAM bank curvature values versus the LCC-derived values. The dashed line shows where a 1:1 correlation of values would fall on the plot. As the interval over which SCREAM calculates curvature decreases the values approach those calculated by the LCC method.

\subsubsection{Mean cumulative width}

Assessment of error in mean cumulative width for sections of single-threaded river

726 channel is straightforward (Section 3.2), however, the mean width and the cumulative width of

727 channel segments will not be equivalent at any point along a multi-threaded river. To our 
728 knowledge, RivWidth is the only other published methodology (Pavelsky \& Smith, 2008) that

729 measures the total width of all channel segments in multi-threaded river systems.

730 The RivWidth methodology (Pavelsky \& Smith, 2008) provides a measure of channel

731 width for both single- and multi-threaded rivers using raster-based binary river masks by

732 determining orthogonals to the channel centerline and counts the number of river pixels that fall

733 on each orthogonal. Assessments performed by Pavelsky \& Smith (2008) and our own

734 application of the code suggest that RivWidth provides accurate measurements of width for

735 single-thread systems and where the individual segments of multi-threaded river run parallel to

736 the specified centerline. In systems with non-parallel channel threads, however, the centerline

737 orthogonal may cross the channel segments at oblique angles resulting in an overestimate of the

738 actual channel width. To provide a comparison of SCREAM and RivWidth (version 4), we ran

739 both on a section of the Strickland River in Papua New Guinea that encompasses single- and

740 multi-threaded channels using the SCREAM-generated segments of the river to average

741 RivWidth output over the same regions of channel. For narrower, single-thread reaches

742 SCREAM and RivWidth estimates agreed closely (Figure 16a), but diverged somewhat at wider,

743 multi-threaded reaches, but the difference between the two types of channels was not

744 significantly different. The segment with the greatest discrepancy (SCREAM $\sim 1,500 \mathrm{~m}$ vs.

745 RivWidth $\sim 750 \mathrm{~m}$ ) had an irregular shape that had a short centerline relative to the total area of

746 the segment resulting in an over-estimate of the width by SCREAM (Figure 16b). In several

747 reaches where RivWidth estimates exceeded SCREAM measurements (points below regression

748 line), individual channel threads ran sub-parallel to the centerline and the RivWidth orthogonals

749 crossed channel threads at oblique angles resulting in over estimates of widths (Figure 16c). 


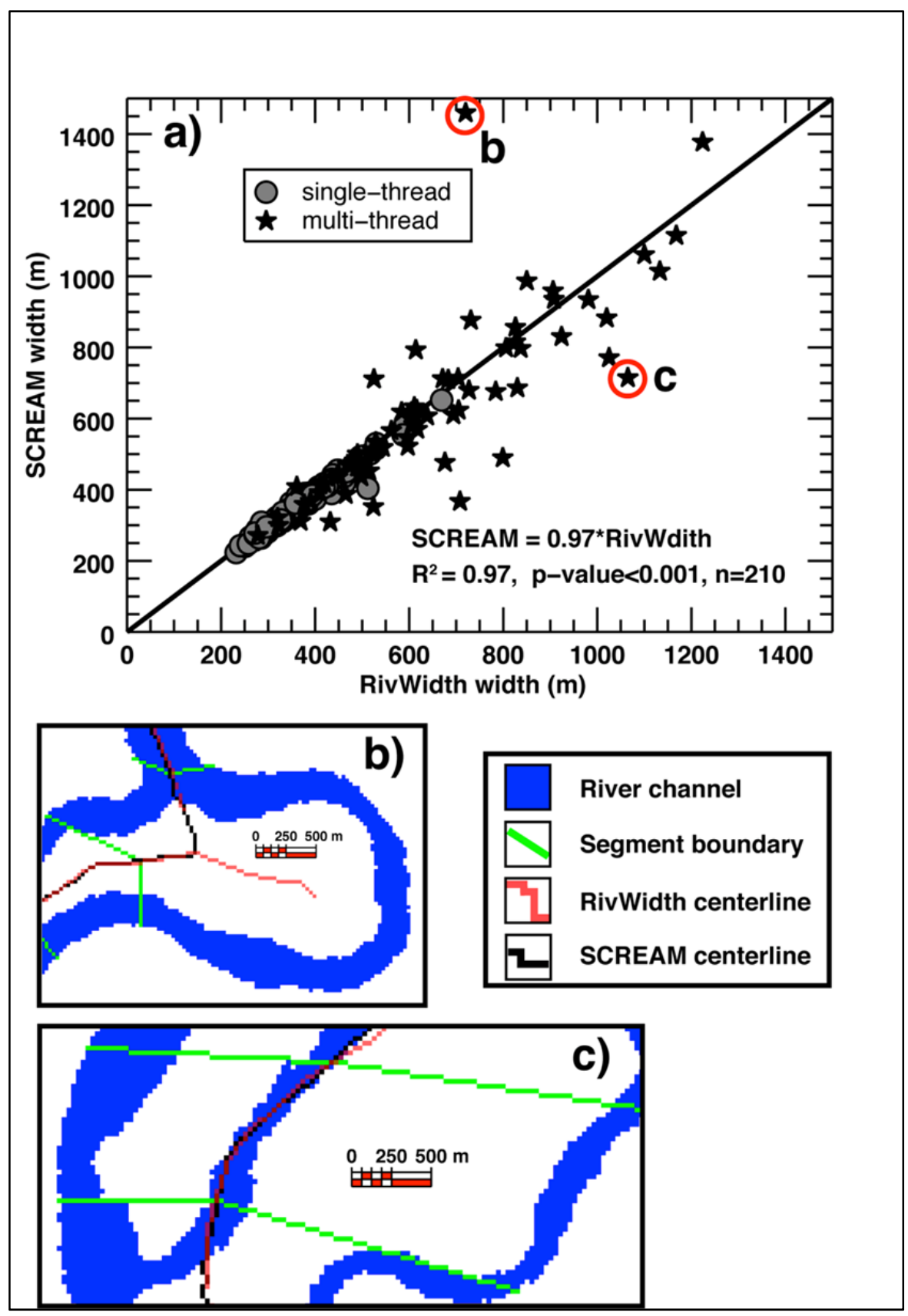

752 Figure 16: A comparison of average cumulative widths (by segment) for a portion of the Strickland River, Papua New Guinea, using both SCREAM and RivWidth (Pavelsky \& Smith, 2008). a) The slope (0.97) and strong fit $\left(\mathrm{R}^{2}=0.97\right.$, $\mathrm{p}$-value $\left.<0.001\right)$ indicate no significant difference between the two methods, but the plot suggests greater ability to measure width for single-threaded channels (filled circles) than for multi-threaded channels (stars). Although channel complexity was not statistically significant, regression analysis (b) indicates that the methods diverge for complex channels as width increases. Panels $\mathrm{b}$ and $\mathrm{c}$ show segments of the 


\section{4. Discussion}

762 Most existing river analysis methods rely on vector-based representations of river

763 channels for input data. SCREAM, along with RivWidth (Pavelsky \& Smith, 2008) and

764 ChanGeom (Fisher, Bookhagen, \& Amos, 2013) are unique in the use of raster-based channel

765 masks for input and analysis. Even though processing vector-based inputs could reduce

766 computational memory requirements associated with raster-based inputs, SCREAM retains the

767 original raster format of the data throughout the analysis, which is advantageous for several

768 reasons. First, the conversion of raster masks, output from feature extraction software, into

769 vector-based representations of channels has the potential to introduce additional sources of error

770 (Congalton, 1997). Second, in several of the SCREAM analysis routines, the ability to perform

771 computational operations on matrices (rasters) increases the efficiency and significantly reduces

772 the number of operations ("for" loops) required. An evaluation of the performance efficiency of

773 SCREAM relative to raster size and channel complexity is presented in Supplemental Materials

774 Section 1 . Third, our original motivation for quantifying river planview change was largely

775 driven by questions of bank erosion dynamics, rather than river channel migration. As such, we

776 adopted a bank-centric approach that allowed an improved ability to examine rates and patterns

777 of bank change due to the retention of the native pixel resolution of the source imagery. By

778 operating in raster space, SCREAM also provides a very detailed view of river width, bank

779 aspects, and the spatial patterns of erosion and accretion rates (Figure 7), allowing direct

780 comparison of patterns of bank change to other spatially distributed datasets such as vegetation,

781 permafrost, or sedimentology of the floodplain. Moreover, extracting measurements at every

782 bank pixel in an input raster generates a very large number of unique measurements to support 
783 spatial statistical analysis of river erosion/accretion rates, widths, and bank aspects. These

784 attributes may be compared at different time intervals for an individual river, used to compare

785 characteristics between river systems, or used to explore relationships between erosion and

786 accretion rates and river geometry.

787 In the process of developing SCREAM we have applied and tested it against a broad

788 range of planform channel morphologies from the simple single-threaded uniform width

789 benchmark channel to the highly complex multi-threaded Yukon River. In all but one test case,

790 the standard error in the SCREAM output, relative to manual measurements, was a fraction of

791 the pixel size of the imagery. We examined the relationship between the errors in width as a

792 function of the size of the width measurement and did not find a relationship. Instead the

793 magnitude of the width errors appears to be related to the complexity of the channel geometry

794 with higher errors occurring for the multi-threaded Yukon River relative to the largely single-

795 threaded Selawik and Strickland Rivers. It appears that this increase in error with channel

796 complexity results from the greater number of islands and a more complex spatial pattern of

797 bank pixels.

798 The ability to examine the relationship between erosion rates and channel curvature at all

799 bank pixels represents a significant opportunity to expand current datasets and rigorously test the

800 control of curvature on bank erosion rates - bend curvature has been linked to bank erosion

801 (Begin, 1986; Hickin, 1974; Hickin \& Nanson, 1975; Hooke \& Yorke, 2010; Nanson \& Hickin,

802 1986), while other studies have not found a clear relationship (Beeson \& Doyle, 1995). Hooke

803 (1980) suggested that normalizing erosion rates by channel width allows for the examination of

804 the relative influence of other factors, such as bank materials, on erosion rates. Plotting width- 
805 normalized erosion rates against width-normalized radii of curvature offers the potential to

806 resolve discrepancies in this relationship.

807 The SCREAM sign convention for curvature allows for erosion and accretion patterns to

808 be assessed both by the magnitude of the curvature and location inside or outside of channels

809 bends. It is commonly assumed that erosion occurs on outer concave banks and accretion occurs

810 on inner convex banks (Hickin \& Nanson, 1984; Wolman \& Leopold, 1957), however, several

811 studies have documented that banks with high curvature and flow separation can result in outer

812 bank accretion creating concave bench deposits (Blanckaert et al., 2013; Nanson \& Page, 1983;

813 Nanson, 2010; Vietz et al., 2012; Woodyer, 1975). SCREAM-generated data provides a tool for

814 a more detailed examination of these dynamics and variability in erosion patterns across a wide

815 variety of river systems.

816 Section 3.2 presented the results of our error assessment of the SCREAM's

817 measurements relative to manual measurements of the same metrics. However, to accurately

818 assess the result of measurements derived from remotely sensed imagery, it is also necessary to

819 account for the impact of image misregistration and classification errors. Table 3 provides a

820 summary of the SCREAM measurements impacted by either or both misregistration and

821 classification errors. We do not list measurements made on a single image, such as width, as

822 affected by misregistration because we assume that the relative location between pixels within a

823 single image is accurate. This assumption may not hold in instances where georectification errors

824 result in local distortions at scales less than a channel width. However, in many of our study sites

825 we do not have sufficient, or any independent ground control points, to assess the absolute

826 accuracy of a single image. Therefore, we limited our misregistration error assessment to the 
827 relative accuracy of one image compared to another based on the location of common features

828 identifiable in each image in the time series being studied.

829 Table 3: Incorporation of Misregistration and Classification Errors

\begin{tabular}{|c|c|c|c|}
\hline $\begin{array}{l}\text { SCREAM } \\
\text { Measurement }\end{array}$ & Misregistration & Classification & Error Incorporation \\
\hline $\begin{array}{l}\text { Linear rate of bank } \\
\text { change }\end{array}$ & $\boldsymbol{v}$ & $\boldsymbol{v}$ & $\begin{array}{l}\text { Error propagation of sums and differences, added in } \\
\text { quadrature }\end{array}$ \\
\hline $\begin{array}{l}\text { Areas of channel } \\
\text { change }\end{array}$ & $\checkmark$ & $\checkmark$ & Supplemental Materials Sections $2 \& 3$ \\
\hline Channel Width & -- & $\checkmark$ & $\begin{array}{c}\text { Error propagation of sums and differences, added in } \\
\text { quadrature }\end{array}$ \\
\hline $\begin{array}{l}\text { Cumulative channel } \\
\text { width }\end{array}$ & -- & $\boldsymbol{v}$ & Supplemental Materials Sections 3 \\
\hline Area of Islands & -- & $\boldsymbol{v}$ & Supplemental Materials Sections 3 \\
\hline Bank Aspects & -- & -- & Not applicable \\
\hline Bank Curvature & -- & -- & Not applicable \\
\hline Sinuosity & -- & -- & Not applicable \\
\hline
\end{tabular}

834 misclassification, impact SCREAM-generated metrics of width and erosion/accretion rates. A

835 detailed description of how such errors may be propagated into measurements of channel width

836 and change in positions of centerlines was provided in Mount et al. (2003) and Mount \& Louis

837 (2005) and therefore is not repeated here. Determination of how misregistration and

838 classification errors affect area-based measurements of change, however, is a much more

839 complex challenge. A number of studies have examined the effect of misregistration on land

840 cover classification and change detection (Dai \& Khorram, 1998; Serra, Pons, \& Sauri, 2003;

841 Van Niel et al., 2008; Verbyla \& Boles, 2000; Wang \& Ellis, 2005) and found that small

842 misregistration errors may result in large classification errors particularly as the number of 
843 classes and image heterogeneity increase (Verbyla \& Boles, 2000; Wang \& Ellis, 2005). While

844 these prior studies highlighted the potential impact of misregistration errors, we are not aware of

845 any study that provides a method for quantifying the error in change-areas given a known

846 misregistration or classification error. In our examination of the impact of misregistration error

847 on change-areas in the rivers we studied, we found that errors in the measurement of change-

848 areas strongly depends on the size of the section of river being analyzed and the distribution of

849 bank aspects in that section. Our complete analysis on the impact of misregistration and

850 misclassification on change-areas along with a methodology for estimating the associated errors

851 is presented in Supplemental Materials Section 2. We highlight that classification errors arising

852 from directional biases in the image, such as shadows, may be explicitly accounted for in

853 SCREAM output since each bank has a recorded aspect. Finally, we discovered a systematic

854 error in measurements that was inherent to measuring distances in a raster-based system.

855 Correcting for this discrepancy represents an area of future improvement and may be solved

856 using Distance Transforms to better estimate actual streamline distances (Butt \& Maragos, 1998;

857 da Paz et al., 2008; de Smith, 2004; Paz \& Collischonn, 2007).

\section{5. Conclusion}

859 The majority of methodologies developed to quantify planview river properties using

860 remotely sensed imagery have been developed for and applied to single-thread rivers (Table 1).

861 Quantification of the planview dynamics of single-thread rivers has commonly relied on analysis

862 of changes in the location of river channel centerlines between successive images. SCREAM

863 differs from most prior methods in its applicability to characterize rivers with both single and

864 multi-threaded planform morphologies, and it uses a bank-based reference frame for quantifying

865 planview properties and change. The utility of this reference frame in analyzing change in 
866 complex channel systems and its provision for a detailed examination of spatial patterns of

867 change and planview properties offers significant opportunities to gain new insights into river

868 dynamics from as fine of a scale as an individual bank pixel to $100 \mathrm{~s}$ and $1,000 \mathrm{~s} \mathrm{~km}$ of a river.

869 SCREAM provides metrics related to both the planview attributes and dynamics of river systems

870 (Table 1). This suite of metrics allows for a detailed examination of individual rivers and for

871 comparing SCREAM-generated results to a broad range of prior studies using alternative

872 methodologies. For example, our comparison with other methodologies suggests that for single-

873 threaded rivers with a stable width, SCREAM-generated rates of linear bank erosion can be

874 accurately compared to lateral migration rates derived from methods measuring change in the

875 lateral position of channel centerlines. Additionally, SCREAM provides area-based

876 measurements of change for comparison to similar prior studies (e.g. Peixoto, Nelson, \&

877 Wittmann, 2009; Rozo, Nogueira, \& Castro, 2014). Readily available remotely sensed imagery

878 of the earth's surface, combined with the increasing ease and sophistication of methods for

879 automatically extracting features from imagery represents an opportunity to quantify river

880 dynamics and planview characteristics at global scales over decadal time spans.

881

882

883

884

885

886

887

888

889

890

891

892

\section{Acknowledgements}

Subsurface and Biogeochemical Research and the Earth System Modeling Programs within the U.S. Department of Energy Office of Science, Biological and Environmental Research supported this work. Initial efforts in the development of these analysis methods were also supported by the U.S. Department of Energy through the LANL/LDRD Program. We thank Wes Lauer for sharing the Strickland River results for comparison in the development of our methods and for providing valuable insights on analysis methodologies. We also thank five anonymous reviewers and Tim McVicar for detailed and constructive comments on earlier versions of the manuscript. 


\section{References Cited}

897

898

Aalto, R., Lauer, J.W., \& Dietrich, W.E. (2008). Spatial and temporal dynamics of sediment accumulation and exchange along Strickland River floodplains (Papua New Guinea) over decadal-to-centennial timescales. J.Geophys.Res, 113, F01S04.

899 Alber, A., \& Piégay, H. (2011). Spatial disaggregation and aggregation procedures for 900 characterizing fluvial features at the network-scale: application to the Rhône basin (France).

901 Geomorphology, 125, 343-360.

902 Allen, G.H., \& Pavelsky, T.M. (2015). Patterns of river width and surface area revealed by the 903 satellite-derived North American River Width data set. Geophysical Research Letters, 42, 395904402.

905 Asahi, K., Shimizu, Y., Nelson, J., \& Parker, G. (2013). Numerical simulation of river

906 meandering with self-evolving banks. Journal of Geophysical Research: Earth Surface, 118, $907 \quad 2208-2229$.

908 Ashworth, P.J., \& Lewin, J. (2012). How do big rivers come to be different? Earth-Science 909 Reviews, 114, 84-107.

910 Baki, A.B.M., \& Gan, T.Y. (2012). Riverbank migration and island dynamics of the braided 911 Jamuna River of the Ganges-Brahmaputra basin using multi-temporal Landsat images.

912 Quaternary International, 263, 148-161.

913 Beeson, C.E., \& Doyle, P.F. (1995). Comparison of bank erosion at vegetated and non-vegetated 914 channel bends. Water Resources Bulletin, 31, 983-990.

915 Begin, Z.B. (1986). Curvature ratio and rate of river bend migration - update. Journal of 916 Hydraulic Engineering-Asce, 112, 904-908.

917 Blanckaert, K., Kleinhans, M.G., McLelland, S.J., Uijttewaal, W.S., Murphy, B.J., Kruijs, A., 918 Parsons, D.R., \& Chen, Q. (2013). Flow separation at the inner (convex) and outer (concave) 919 banks of constant-width and widening open-channel bends. Earth Surface Processes and 920 Landforms, 38, 696-716.

921 Brice, J. (1977). Lateral migration of the Middle Sacramento River, California. USGS Water922 Resources Investigations, 77-43, 51.

923 Brumby, S.P., Theiler, J., Perkins, S.J., Harvey, N.J., Szymanski, J.J., Bloch, J.J., \& Mitchell, M. 924 (1999). Investigation of image feature extraction by a genetic algorithm. In, SPIE's International 925 Symposium on Optical Science, Engineering, and Instrumentation (pp. 24-31): International 926 Society for Optics and Photonics.

927 Butt, M.A., \& Maragos, P. (1998). Optimum design of chamfer distance transforms. Image 928 Processing, IEEE Transactions on, 7, 1477-1484. 
929 Church, M. (2006). Bed material transport and the morphology of alluvial river channels. Annu. 930 Rev. Earth Planet. Sci., 34, 325-354.

931 Church, M., \& Xu, J. (2015). Post-Regulation Morphological Change on Peace River. The 932 Regulation of Peace River: A Case Study for River Management (pp. 141-174): John Wiley \& 933 Sons, Ltd..

934 Congalton, R.G. (1997). Exploring and evaluating the consequences of vector-to-raster and 935 raster-to-vector conversion. Photogrammetric Engineering and Remote Sensing, 63, 425-434.

936 Congalton, R.G., \& Green, K. (2008). Assessing the accuracy of remotely sensed data: principles 937 and practices. CRC press.

938 Constantine, C.R., Dunne, T., \& Hanson, G.J. (2009). Examining the physical meaning of the 939 bank erosion coefficient used in meander migration modeling. Geomorphology, 106, 242-252.

940 Constantine, J.A., Dunne, T., Ahmed, J., Legleiter, C., \& Lazarus, E.D. (2014). Sediment supply 941 as a driver of river meandering and floodplain evolution in the Amazon Basin. Nature

942 Geoscience, 7, 899-903.

943 Costard, F., \& Gautier, E. (2008). The Lena River: hydromorphodynamic features in a deep 944 permafrost zone. Large Rivers: Geomorphology and Management, 225-233.

945 Costard, F., Gautier, E., Brunstein, D., Hammadi, J., Fedorov, A., Yang, D., \& Dupeyrat, L. 946 (2007). Impact of the global warming on the fluvial thermal erosion over the Lena River in 947 Central Siberia. Geophysical Research Letters, 34, L14501.

948 da Paz, A.R., Collischonn, W., Risso, A., \& Mendes, C.A.B. (2008). Errors in river lengths 949 derived from raster digital elevation models. Computers \& Geosciences, 34, 1584-1596.

950 Dai, X., \& Khorram, S. (1998). The effects of image misregistration on the accuracy of remotely 951 sensed change detection. Geoscience and Remote Sensing, IEEE Transactions on, 36, 15669521577.

953 Darby, S.E., Trieu, H.Q., Carling, P.A., Sarkkula, J., Koponen, J., Kummu, M., Conlan, I., \& 954 Leyland, J. (2010). A physically based model to predict hydraulic erosion of fine-grained 955 riverbanks: The role of form roughness in limiting erosion. Journal of Geophysical Research: 956 Earth Surface (2003-2012), 115.

957 de Smith, M.J. (2004). Distance transforms as a new tool in spatial analysis, urban planning, and 958 GIS. Environment and planning B: Planning and design, 31, 85-104.

959 Dey, A., \& Bhattacharya, R.K. (2013). Monitoring of River Center Line and Width-A Study on 960 River Brahmaputra. Journal of the Indian Society of Remote Sensing, 1-8.

961 Dillabaugh, C.R., Niemann, K.O., \& Richardson, D.E. (2002). Semi-automated extraction of 962 rivers from digital imagery. GeoInformatica, 6, 263-284. 
Downward, S., Gurnell, A., \& Brookes, A. (1994). A methodology for quantifying river channel planform change using GIS. IAHS Publications-Series of Proceedings and Reports-Intern Assoc 965 Hydrological Sciences, 224, 449-456.

966 Eke, E., Parker, G., \& Shimizu, Y. (2014). Numerical modeling of erosional and depositional 967 bank processes in migrating river bends with self-formed width: Morphodynamics of bar push 968 and bank pull. Journal of Geophysical Research: Earth Surface, 119, 1455-1483.

969 Eke, E.C., Czapiga, M., Viparelli, E., Shimizu, Y., Imran, J., Sun, T., \& Parker, G. (2014). 970 Coevolution of width and sinuosity in meandering rivers. Journal of Fluid Mechanics, 760, 127971174.

972 Fagherazzi, S., Gabet, E.J., \& Furbish, D.J. (2004). The effect of bidirectional flow on tidal 973 channel planforms. Earth Surface Processes and Landforms, 29, 295-309.

974 Fisher, G.B., Bookhagen, B., \& Amos, C.B. (2013). Channel planform geometry and slopes from 975 freely available high-spatial resolution imagery and DEM fusion: Implications for channel width 976 scalings, erosion proxies, and fluvial signatures in tectonically active landscapes.

977 Geomorphology, 194, 46-56.

978 Gangodagamage, C., Barnes, E., \& Foufoula-Georgiou, E. (2007). Scaling in river corridor 979 widths depicts organization in valley morphology. Geomorphology, 91, 198-215.

980 Gautier, E., Brunstein, D., Costard, F., \& Lodina, R. (2003). Fluvial dynamics in a deep 981 permafrost zone: the case of the Middle Lena river (central Siberia). In, Eighth International 982 Conference on Permafrost, Zurich (pp. 271-275).

983 Gleason, C.J., \& Smith, L.C. (2014). Toward global mapping of river discharge using satellite 984 images and at-many-stations hydraulic geometry. Proceedings of the National Academy of 985 Sciences, 111, 4788-4791.

986 Grabowski, R.C., Surian, N., \& Gurnell, A.M. (2014). Characterizing geomorphological change 987 to support sustainable river restoration and management. Wiley Interdisciplinary Reviews: Water, $9881,483-512$.

989 Graham, D.J., Reid, I., \& Rice, S.P. (2005). Automated sizing of coarse-grained sediments: 990 image-processing procedures. Mathematical Geology, 37, 1-28.

991 Güneralp, İ., \& Rhoads, B.L. (2008). Continuous characterization of the planform geometry and 992 curvature of meandering rivers. Geographical Analysis, 40, 1-25.

993 Gurnell, A. (1997a). Adjustments in river channel geometry associated with hydraulic 994 discontinuities across the fluvial-tidal transition of a regulated river. Earth Surface Processes 995 and Landforms, 22, 967-985.

996 Gurnell, A.M. (1997b). Channel change on the River Dee meanders, 1946-1992, from the 997 analysis of air photographs. Regulated Rivers-Research \& Management, 13, 13-26. 
998 Gurnell, A.M., Downward, S.R., \& Jones, R. (1994). Channel planform change on the River Dee 999 meanders, 1876-1992. Regulated Rivers-Research \& Management, 9, 187-204.

1000 Hamilton, S.K., Kellndorfer, J., Lehner, B., \& Tobler, M. (2007). Remote sensing of floodplain 1001 geomorphology as a surrogate for biodiversity in a tropical river system (Madre de Dios, Peru). 1002 Geomorphology, 89, 23-38.

1003 Hickin, E.J. (1974). Development of meanders in natural river-channels. American Journal of 1004 Science, 274, 414-442.

1005 Hickin, E.J., \& Nanson, G.C. (1975). The character of channel migration on the Beatton River, 1006 northeast British Columbia, Canada. Geological Society of America Bulletin, 86, 487-494.

1007 Hickin, E.J., \& Nanson, G.C. (1984). Lateral migration rates of river bends. Journal of Hydraulic 1008 Engineering, 110, 1557-1567.

1009 Hooke, J. (1980). Magnitude and distribution of rates of river bank erosion. Earth surface 1010 processes, 5, 143-157.

1011 Hooke, J. (1984). Changes in river meanders a review of techniques and results of analyses. 1012 Progress in Physical Geography, 8, 473-508.

1013 Hooke, J., \& Harvey, A. (1983). Meander changes in relation to bend morphology and secondary 1014 flows. Modern and Ancient Fluvial Systems: Special Publication 6 of the IAS, 121.

1015 Hooke, J., \& Yorke, L. (2010). Rates, distributions and mechanisms of change in meander 1016 morphology over decadal timescales, River Dane, UK. Earth Surface Processes and Landforms, 1017 35, 1601-1614.

1018 Hossain, M.A., Gan, T.Y., \& Baki, A.B.M. (2013). Assessing morphological changes of the 1019 Ganges River using satellite images. Quaternary International, 304, 142-155.

1020 James, L.A., Hodgson, M.E., Ghoshal, S., \& Latiolais, M.M. (2012). Geomorphic change 1021 detection using historic maps and DEM differencing: The temporal dimension of geospatial 1022 analysis. Geomorphology, 137, 181-198.

1023 Kean, J.W., \& Smith, J.D. (2006a). Form drag in rivers due to small-scale natural topographic 1024 features: 1. Regular sequences. Journal of Geophysical Research: Earth Surface (2003-2012), 1025111.

1026 Kean, J.W., \& Smith, J.D. (2006b). Form drag in rivers due to small-scale natural topographic 1027 features: 2. Irregular sequences. Journal of Geophysical Research: Earth Surface (2003-2012), 1028111.

1029 Knighton, D. (1998). Fluvial forms and processes: a new perspective. Arnold, Hodder Headline, 1030 PLC. 
1031 Konrad, C., Berge, H., Fuerstenberg, R., Steff, K., Olsen, T., \& Guyenet, J. (2011). Channel 1032 dynamics in the Middle Green River, Washington, from 1936 to 2002. Northwest Science, 85, 1103314.

1034 Lagasse, P.F., Spitz, W.J., Zevenbergen, L.W., \& Zachmann, D.W. (2004). Handbook for 1035 predicting stream meander migrationTransportation Research Board, N.C.H.R. PROGRAM, (p. 1036 107).

1037 Latrubesse, E.M. (2008). Patterns of anabranching channels: The ultimate end-member 1038 adjustment of mega rivers. Geomorphology, 101, 130-145.

1039 Lauer, J.W., \& Parker, G. (2008a). Modeling framework for sediment deposition, storage, and 1040 evacuation in the floodplain of a meandering river: Theory. Water Resources Research, 44.

1041 Lauer, J.W., \& Parker, G. (2008b). Net local removal of floodplain sediment by river meander 1042 migration. Geomorphology, 96, 123-149.

1043 Lawler, D. (1986). River bank erosion and the influence of frost: a statistical examination. 1044 Transactions of the Institute of British Geographers, 227-242.

1045 Lawler, D.M. (1993). The measurement of river bank erosion and lateral channel change: a 1046 review. Earth Surface Processes and Landforms, 18, 777-821.

1047 Legleiter, C.J., \& Kyriakidis, P.C. (2006). Forward and inverse transformations between 1048 Cartesian and channel-fitted coordinate systems for meandering rivers. Mathematical Geology, $104938,927-958$.

1050 Leopold, L.B. (1973). River channel change with time: an example address as Retiring President 1051 of The Geological Society of America, Minneapolis, Minnesota, November 1972. Geological 1052 Society of America Bulletin, 84, 1845-1860.

1053 Leys, K.F., \& Werritty, A. (1999). River channel planform change: software for historical 1054 analysis. Geomorphology, 29, 107-120.

1055 Marra, W.A., Kleinhans, M.G., \& Addink, E.A. (2014). Network concepts to describe channel 1056 importance and change in multichannel systems: test results for the Jamuna River, Bangladesh. 1057 Earth Surface Processes and Landforms, 39, 766-778.

1058 McFeeters, S. (1996). The use of the Normalized Difference Water Index (NDWI) in the 1059 delineation of open water features. International Journal of Remote Sensing, 17, 1425-1432.

1060 Mertes, L.A.K., Dunne, T., \& Martinelli, L.A. (1996). Channel-floodplain geomorphology along 1061 the Solimoes-Amazon River, Brazil. Geological Society of America Bulletin, 108, 1089-1107.

1062 Merwade, V.M. (2007). An Automated GIS Procedure for Delineating River and Lake 1063 Boundaries. Transactions in GIS, 11, 213-231. 
1064 Micheli, E., Kirchner, J., \& Larsen, E. (2004). Quantifying the effect of riparian forest versus 1065 agricultural vegetation on river meander migration rates, Central Sacramento River, California, 1066 USA. River Research and Applications, 20, 537-548.

1067 Micheli, E., \& Larsen, E. (2011). River channel cutoff dynamics, Sacramento river, California, 1068 USA. River Research and Applications, 27, 328-344.

1069 Micheli, E.R., \& Kirchner, J.W. (2002). Effects of wet meadow riparian vegetation on 1070 streambank erosion. 1. Remote sensing measurements of streambank migration and erodibility. 1071 Earth Surface Processes and Landforms, 27, 627-639.

1072 Mount, N., \& Louis, J. (2005). Estimation and propagation of error in measurements of river 1073 channel movement from aerial imagery. Earth Surface Processes and Landforms, 30, 635-643.

1074 Mount, N., Louis, J., Teeuw, R., Zukowskyj, P., \& Stott, T. (2003). Estimation of error in 1075 bankfull width comparisons from temporally sequenced raw and corrected aerial photographs. 1076 Geomorphology, 56, 65-77.

1077 Mount, N.J., Tate, N.J., Sarker, M.H., \& Thorne, C.R. (2012). Evolutionary, multi-scale analysis 1078 of river bank line retreat using continuous wavelet transforms: Jamuna River, Bangladesh. 1079 Geomorphology.

1080 Nanson, G.C., \& Hickin, E.J. (1983). Channel migration and incision on the Beatton River. 1081 Journal of Hydraulic Engineering, 109, 327-337.

1082 Nanson, G.C., \& Hickin, E.J. (1986). A statistical analysis of bank erosion and channel migration 1083 in western Canada. Geological Society of America Bulletin, 97, 497-504.

1084 Nanson, G.C., \& Page, K. (1983). Lateral accretion of fine-grained concave benches on 1085 meandering rivers. Modern and Ancient Fluvial Systems (Special Publication 6 of the IAS), 133.

1086 Nanson, R.A. (2010). Flow fields in tightly curving meander bends of low width-depth ratio. 1087 Earth Surface Processes and Landforms, 35, 119-135.

1088 Nash, J., \& Sutcliffe, J. (1970). River flow forecasting through conceptual models part I-A 1089 discussion of principles. Journal of Hydrology, 10, 282-290.

1090 Notebaert, B., \& Piégay, H. (2013). Multi-scale factors controlling the pattern of floodplain 1091 width at a network scale: The case of the Rhône basin, France. Geomorphology, 200, 155-171.

1092 Parker, G., Shimizu, Y., Wilkerson, G., Eke, E., Abad, J., Lauer, J., Paola, C., Dietrich, W., \& 1093 Voller, V. (2011). A new framework for modeling the migration of meandering rivers. Earth 1094 Surface Processes and Landforms, 36, 70-86.

1095 Pavelsky, T.M., \& Smith, L.C. (2008). RivWidth: A software tool for the calculation of river 1096 widths from remotely sensed imagery. Ieee Geoscience and Remote Sensing Letters, 5, 70-73. 
1097 Paz, A.R., \& Collischonn, W. (2007). River reach length and slope estimates for large-scale 1098 hydrological models based on a relatively high-resolution digital elevation model. Journal of 1099 Hydrology, 343, 127-139.

1100 Peixoto, J.M.A., Nelson, B.W., \& Wittmann, F. (2009). Spatial and temporal dynamics of river 1101 channel migration and vegetation in central Amazonian white-water floodplains by remote1102 sensing techniques. Remote Sensing of Environment, 113, 2258-2266.

1103 Perkins, S.J., Edlund, K., Esch-Mosher, D., Eads, D., Harvey, N., \& Brumby, S. (2005). Genie 1104 Pro: Robust image classification using shape, texture, and spectral information. Proceedings of 1105 SPIE, 5806, 139-148.

1106 Pizzuto, J. (2009). An empirical model of event scale cohesive bank profile evolution. Earth 1107 Surface Processes and Landforms, 34, 1234-1244.

1108 Priestnall, G., \& Aplin, P. (2006). Spatial and temporal remote sensing requirements for river 1109 monitoring. International Journal of Remote Sensing, 27, 2111-2120.

1110 Quackenbush, L.J. (2004). A review of techniques for extracting linear features from imagery. 1111 Photogrammetric Engineering \& Remote Sensing, 70, 1383-1392.

1112 Richard, G.A., Julien, P.Y., \& Baird, D.C. (2005). Statistical analysis of lateral migration of the 1113 Rio Grande, New Mexico. Geomorphology, 71, 139-155.

1114 Rozo, M.G., Nogueira, A.C., \& Castro, C.S. (2014). Remote sensing-based analysis of the 1115 planform changes in the Upper Amazon River over the period 1986-2006. Journal of South 1116 American Earth Sciences, 51, 28-44.

1117 Serra, P., Pons, X., \& Sauri, D. (2003). Post-classification change detection with data from 1118 different sensors: some accuracy considerations. International Journal of Remote Sensing, 24, 1119 3311-3340.

1120 Shields, F.D., Simon, A., \& Steffen, L.J. (2000). Reservoir effects on downstream river channel 1121 migration. Environmental Conservation, 27, 54-66.

1122 Smith, L.C., \& Pavelsky, T.M. (2008). Estimation of river discharge, propagation speed, and 1123 hydraulic geometry from space: Lena River, Siberia. Water Resources Research, 44.

1124 Snow, R.S. (1989). Fractal sinuosity of stream channels. pure and applied geophysics, 131, 991125109.

1126 Thorne, C.R., \& Tovey, N.K. (1981). Stability of composite river banks. Earth Surface 1127 Processes and Landforms, 6, 469-484.

1128 Van Niel, T.G., McVicar, T.R., Li, L., Gallant, J.C., \& Yang, Q. (2008). The impact of 1129 misregistration on SRTM and DEM image differences. Remote Sensing of Environment, 112, 1130 2430-2442. 
1131 Verbyla, D., \& Boles, S. (2000). Bias in land cover change estimates due to misregistration.

1132 International Journal of Remote Sensing, 21, 3553-3560.

1133 Vietz, G.J., Rutherfurd, I.D., Stewardson, M.J., \& Finlayson, B.L. (2012). Hydrodynamics and 1134 sedimentology of concave benches in a lowland river. Geomorphology, 147, 86-101.

1135 Wang, H., \& Ellis, E.C. (2005). Image misregistration error in change measurements.

1136 Photogrammetric Engineering \& Remote Sensing, 71, 1037-1044.

1137 Wheaton, J.M., Brasington, J., Darby, S.E., \& Sear, D.A. (2010). Accounting for uncertainty in 1138 DEMs from repeat topographic surveys: improved sediment budgets. Earth Surface Processes 1139 and Landforms, 35, 136-156.

1140 Winterbottom, S.J., \& Gilvear, D.J. (2000). A GIS-based approach to mapping probabilities of 1141 river bank erosion: regulated River Tummel, Scotland. Regulated Rivers: Research \& 1142 Management, 16, 127-140.

1143 Wolman, M. (1959). Factors influencing erosion of a cohesive river bank. American Journal of 1144 Science, 257, 204-216.

1145 Wolman, M.G., \& Leopold, L.B. (1957). River flood plains; some observations on their 1146 formation, .

1147 Woodyer, K. (1975). Concave-bank benches on Barwon River, NSW. Australian Geographer, 1148 13, 36-40.

1149 Wynn, T., Henderson, M., \& Vaughan, D. (2008). Changes in streambank erodibility and critical 1150 shear stress due to subaerial processes along a headwater stream, southwestern Virginia, USA. 1151 Geomorphology, 97, 260-273.

$1152 \mathrm{Xu}, \mathrm{H}$. (2006). Modification of normalised difference water index (NDWI) to enhance open 1153 water features in remotely sensed imagery. International Journal of Remote Sensing, 27, 302511543033.

1155 Yamazaki, D., O'Loughlin, F., Trigg, M.A., Miller, Z.F., Pavelsky, T.M., \& Bates, P.D. (2014). 1156 Development of the global width database for large rivers. Water Resources Research, 50, 346711573480.

1158 Yumoto, M., Ogata, T., Matsuoka, N., \& Matsumoto, E. (2006). Riverbank freeze-thaw erosion 1159 along a small mountain stream, Nikko volcanic area, central Japan. Permafrost and Periglacial 1160 Processes, 17, 325-339.

1161 Zar, J.H. (1999). Biostatistical analysis. (4th ed.). New Jersey: Prentice-Hall, Inc..

1162 Zolezzi, G., Luchi, R., \& Tubino, M. (2012a). Modeling morphodynamic processes in 1163 meandering rivers with spatial width variations. Reviews of Geophysics, 50, RG4005. 
1164 Zolezzi, G., Luchi, R., \& Tubino, M. (2012b). Modeling morphodynamic processes in 1165 meandering rivers with spatial width variations. Reviews of Geophysics, 50.

1166

1167 
1171 Figure 1: Three hypothetical changes in channel position between Time 1 and Time 2 having

1172 equal areas of erosion of the bounding floodplain but differing channel centerline migration

1173 (dashed lines). a) The channel shifts laterally 50m, with equal areas of erosion and deposition on

1174 opposite sides of the channel. b) The channel at Time 2 widens by $50 \mathrm{~m}$ on one side, the average

1175 linear erosion along the banks is $50 \mathrm{~m}$, but the migration of channel centerlines is only $25 \mathrm{~m} . \mathrm{c}$ )

1176 The channel widens by $50 \mathrm{~m}$ by eroding $25 \mathrm{~m}$ along each channel margin. The total erosion

1177 along the channel is the same as a and $\mathrm{b}$, but the migration of the centerline indicates $0 \mathrm{~m}$ of

1178 change.

1179

1180 Figure 2: a) Two binary masks of a portion of the Selawik River, Alaska derived from

1181 September 24 and 29, 2009 Geoeye images (red) and July 25, 1981 Alaska High Altitude

1182 Photography (AHAP) (blue). Areas of red not overlain by the blue mask represent areas of the

1183 floodplain that eroded. Areas labeled "Sweep" mark places where the channel eroded more than

1184 a channel width. Areas where the channel jumped to a new location are labeled as "Avulsion" or

1185 “Cutoff”. b) Areas experiencing erosion, accretion, and both erosion and accretion.

1187 Figure 3: Graphical illustration of the determination of erosion distances (the method is identical

1188 for accretion). a) A distance map (the colored pixels) is generated for each unique bank segment

1189 from the Time 2 channel mask (red line) and intersected with the Time 1 bank pixels (black). A

1190 linear rate of bank change is calculated by dividing the distance values by the time interval. b)

1191 Measurement of erosion distances for an island that completely erodes between Time 1 and Time 
1192 2. The distance map is created from the pixel(s) in the interior of the island (white pixel in

1193 colored region) that were furthest from any bank on the island perimeter at Time 1 . The distances

1194 from bank pixels (black) to this interior point are determined by intersection with the distance

1195 map.

1196

1197 Figure 4: An illustration of the determination of channel width. The red lines represents the

1198 shortest distance from a bank pixel to another bank line; the white dashed indicate the 40-degree

1199 screening window; and the green lines are the shortest paths the screening window from a target

1200 pixel (yellow) to the other bank.

1201

1202 Figure 5: An example of a portion of the Yukon River binary channel mask showing

1203 segmentation boundaries (red) and the centerline along which channel distances were calculated

1204 (green). The sections boundaries are evenly spaced along the centerline, but do not have equal

1205 areas. The black points mark the midpoint of the section on the centerline.

1206

1207 Figure 6: Images of portions of the river channels analyzed by SCREAM: a) the Selawik River

1208 in northwest Alaska (September 24, 2009 Geoeye 2m false color image (near infrared, red, and

1209 green bands)). b) the Strickland River, Papua New Guinea (March 26, 1993 Landsat 5 30m

1210 natural color (Bands 3,2,1), path 65, row 99). c) the Yukon River, Alaska (August 23, 2008

1211 Landsat $530 \mathrm{~m}$ natural color composite (Bands 3, 2, 1), path 69, row 13) at 30m/pixel resolution

1212 (image id: L5069013_01320080823). d) the Yukon River (1974 color infrared aerial photograph

1213 scanned with a $2.5 \mathrm{~m} /$ pixel resolution).

1214 
1215 Figure 7: Raster-based output from SCREAM. a) Bank pixels showing erosion rates between

12161986 and 2008 of a small portion of the Yukon River. The bank pixel locations correspond to the

1217 channel banks in 1986 the underlying panchromatic image was collected in 2008 by Landsat 5.

1218 b) Accretion rates between 1986 and 2008 shown at the 2008 bank locations in scaled colors

1219 overlain on the panchromatic image. c) Local channel widths for all 1986 bank pixels. d) Aspects

1220 of the banks in 1986. Discharge measured at the Stevens Village gauge $90 \mathrm{~km}$ downstream

1221 (USGS ID: 15453500) was 10,250 cubic meter per second (cms) on June 15, 1986 and 6,230

1222 cms on August 30, 2008. The Landsat images were collected on June 15, 1986 (path 70, row 13)

1223 for panels b-d and August 20, 2008 (path 70, row 13) for panel a.

1224

1225 Figure 8: Histograms of local channel widths generated from the 1986 mask of the Yukon River 1226 and the 1993 channel mask of the Strickland River.

1228 Figure 9: a) The distribution of all bank aspects for the 1986 mask of the Yukon River. The

1229 dashed circles indicate the count of bank aspects within each aspect bin. b) Mean erosion rates

1230 by bank aspect binned in 10 degree increments. The erosion rates were determined based on

1231 changes in the river between 1986 and 1994. The dashed inner circles indicate erosion rates

1232 ranging from 0 to $4 \mathrm{~m} / \mathrm{yr}$.

1233

1234 Figure 10: Erosion (a) and accretion (b) rates averaged at regularly spaced intervals along the 1235 Yukon River for the time period of 1986 to 2008. 
1236 Figure 11: Total area of eroded and accreted floodplain for a portion of the Yukon River

1237 between 1986 and 2008. The areas of accretion exceed erosion for a large portion of the reach,

1238 an imbalance that reflects the infilling of the several large oxbows.

1239

1240 Figure 12: Measured widths for a portion of the Selawik River, Alaska from a 1981 aerial

1241 photograph-derived channel mask. The mean channel width calculated at evenly spaced intervals

1242 is shown in black and the average cumulative channel width of each segment is displayed in

1243 blue. Where there is only a single channel thread in a segment the mean and cumulative widths

1244 are equal.

1245

1246 Figure 13: Synthetic river channel generated using a periodic function with constant width 1247

1248 Figure 14: A comparison SCREAM erosion rates for synthetic channel (Figure 13) averaged

1249 over $100 \mathrm{~m}$ long segments (blue line) against lateral migration rates determined using the

1250 Planform Statistics Toolbox (Aalto, Lauer, \& Dietrich, 2008) calculated at evenly spaced

1251 intervals of 25 (red line) and $100 \mathrm{~m}$ (black line) along the channel.

1252

1253 Figure 15: Comparison of bank curvature values from SCREAM to curvature determined using

1254 LCC (Legleiter \& Kyriakidis, 2006). The comparison was performed on the top bank in the Time

12551 synthetic raster (Figure 13). a) The black lines show the curvature values obtained using

1256 smoothed data, LCC, and a $3^{\text {rd }}$ order polynomial to fit a line to the bank pixels and the data was

1257 smoothed 5 times prior to fitting the polynomial. The SCREAM calculated curvature values

1258 were obtained using distance intervals of $1 / 2,2$, and 4 channel widths (red, green, and blue lines 
1259 respectively). b) a scatter plot showing SCREAM bank curvature values versus the LCC-derived

1260 values. The dashed line shows where a 1:1 correlation of values would fall on the plot. As the

1261 interval over which SCREAM calculates curvature decreases the values approach those

1262 calculated by the LCC method.

1263

1264 Figure 16: A comparison of average cumulative widths (by segment) for a portion of the

1265 Strickland River, Papua New Guinea, using both SCREAM and RivWidth (Pavelsky \& Smith,

1266 2008). a) The slope $(0.97)$ and strong fit $\left(\mathrm{R}^{2}=0.97\right.$, $\mathrm{p}$-value $\left.<0.001\right)$ indicate no significant

1267 difference between the two methods, but the plot suggests greater ability to measure width for

1268 single-threaded channels (filled circles) than for multi-threaded channels (stars). Although

1269 channel complexity was not statistically significant, regression analysis (b) indicates that the

1270 methods diverge for complex channels as width increases. Panels $\mathrm{b}$ and $\mathrm{c}$ show segments of the

1271 river where the SCREAM and RivWidth measurements provide differing width measurements.

1272 